\title{
Diversity of species of the genus Conocybe (Bolbitiaceae, Agaricales) collected on dung from Punjab, India
}

\author{
Amandeep $\mathrm{K}^{1^{*}}$, Atri $\mathrm{NS}^{2}$ and Munruchi $\mathrm{K}^{2}$ \\ ${ }^{I}$ Desh Bhagat College of Education, Bardwal-Dhuri-148024, Punjab, India \\ ${ }^{2}$ Department of Botany, Punjabi University, Patiala-147002, Punjab, India.
}

Amandeep K, Atri NS, Munruchi K 2015 - Diversity of species of the genus Conocybe (Bolbitiaceae, Agaricales) collected on dung from Punjab, India. Mycosphere 6(1), 19-42, Doi 10.5943/mycosphere/6/1/4

\begin{abstract}
A study of diversity of coprophilous species of Conocybe was carried out in Punjab state of India during the years 2007 to 2011. This research paper represents 22 collections belonging to 16 Conocybe species growing on five diverse dung types. The species include Conocybe albipes, $C$. apala, C. brachypodii, C. crispa, C. fuscimarginata, C. lenticulospora, C. leucopus, C. magnicapitata, C. microrrhiza var. coprophila var. nov., C. moseri, C. rickenii, C. subpubescens, C. subxerophytica var. subxerophytica, $C$. subxerophytica var. brunnea, $C$. uralensis and $C$. velutipes. For all these taxa, dung types on which they were found growing are mentioned and their distinctive characters are described and compared with similar taxa along with a key for their identification. The taxonomy of ten taxa is discussed along with the drawings of morphological and anatomical features. Conocybe microrrhiza var. coprophila is proposed as a new variety. As many as six taxa, namely $C$. albipes, $C$. fuscimarginata, $C$. lenticulospora, $C$. leucopus, $C$. moseri and $C$. subpubescens are the first time records from India. Conocybe velutipes is the first time record from North India.
\end{abstract}

Key Words - Basidiomycota - dung - hymeniform - lecythiform - taxonomy

\section{Introduction}

The genus Conocybe belongs to the family Bolbitiaceae and can be separated from the other genera of the family by lecythiform cheilocystidia with a round capitellum and pileal margin not plicate-sulcate. It is characterized by its delicate carpophores which are small to medium sized and are reported to grow on a variety of substrates such as on the ground, in woods, pastures, gardens, etc. and on dung, occasionally attached to plant remains and vegetable refuse, sometimes even on sand dunes as discussed by Singer (1986), Pegler (1977, 1983, 1986).

Kirk et al. (2008) recognized 200 species of Conocybe the world over. From India, about 30 species of Conocybe are known (Bilgrami et al. 1991, Saini \& Atri 1995, Natarajan et al. 2005, Atri et al. 2009, 2012, Kumar et al. 2014). Natarajan \& Raaman (2005) reported 03 species, namely $C$. ambigua (Kühner) Sing.: Sing., C. plumbeitincta (Atk.) Singer and C. semiglobata Kühner: Singer as growing on cow dung from Tamil Nadu state in India. Thomas et al. (2001) reported three species, namely C. pseudopubescens K. A. Thomas, Hauskn. \& Manimohan, C. volvata K. A. Thomas, Hauskn. \& Manimohan growing on elephant dung and $C$. zeylanica (Petch) Boedijn on a 
heap of dried cow dung from Kerala state. Manimohan et al. (2007) reported three species, namely C. brunneoaurantiaca K. A. Thomas, Hauskn. \& Manimohan, C. pseudopubescens and C. volvata, growing on elephant dung from Kerala. From Punjab state, eight species, viz. C. ambigua, C. apala (Fr.) Arnolds, C. brachypodii (Velen.) Hauskn. et Svrček, C. crispa (Longyear) Singer, C. rickenii (Schaef.) Kühner, C. subxerophytica var. subxerophytica Singer \& Hauskn., C. subxerophytica var. brunnea Hauskn. and C. uralensis Hauskn., Knudsen \& Mukhin have already been documented (Sarwal \& Rawla 1983, Atri et al. 1992, 2009, 2012). Out of these, C. rickenii was reported from horse dung (Sarwal \& Rawla 1983), C. brachypodii and C. crispa on cattle dung (Atri et al. 2009) and $C$. apala, $C$. subxerophytica var. subxerophytica, $C$. subxerophytica var. brunnea and $C$. uralensis on buffalo dung (Atri et al. 2012).

\section{Materials \& Methods}

Study Area - The state of Punjab is located in the north-western part of India, located between $29^{\circ} 32^{\prime}$ to $32^{\circ} 32^{\prime} \mathrm{N}$ latitude and $73^{\circ} 55^{\prime}$ to $76^{\circ} 70^{\prime} \mathrm{E}$ longitude and it covers an area of 50,362 sq. $\mathrm{km}$. which constitutes $1.57 \%$ of the total area of country. Its average elevation is about $300 \mathrm{~m}$ from the sea level. Climatically, Punjab has four major seasons- summer, monsoon, winter and autumn season. The amount of rainfall in Punjab ranges between $250 \mathrm{~mm}$ to $1000 \mathrm{~mm}$. Most of the annual rainfall is experienced during the arrival of southwest monsoon in the region. About 70-80\% of the total rainfall is concentrated during July, August and September and the rest occurs during the winter months. The study area has seven to eight months of mean monthly temperature of more than $20^{\circ} \mathrm{C}$. It is primarily an agrarian state having diverse flora and fauna. Various domesticated and wild herbivorous animals are found on the grazing lands of the state. Of the total livestock, about $90 \%$ are cattle and buffaloes and the rest sheep, goats, camels and other animals which are domesticated for their use in agriculture, dairy, transportation and various other purposes.

Collection, Preservation and Observation - All descriptions are based on the specimens collected from different dung localities in Punjab explored during the years 2007 to 2011. The macroscopic features of the collected materials including pileus and stipe dimensions, surface features, colour, lamellar spacing, and attachment, habit and dung substrate, etc. were observed and recorded from the fresh material and documented on the field key (Atri \& Saini 2000, Atri et al. 2005). The terminology of Kornerup \& Wanscher (1978) was used for recording the color of various parts of the carpophore, and spore print, etc. After studying the macroscopic characters, the collected mushrooms were hot air dried in a drier especially designed for this purpose (Atri et al. 2005). The mushrooms were finally packed in the moisture proof cellophane paper packets along with the collection number. To avoid insect infestations small packs of crystals of 1-4 Paradichlorobenzene were placed in these packets (Smith 1949, Atri \& Saini 2000). The hand cut sections of various parts of carpophore such as pileus, gills, stipe and basidiospores details were studied under the microscope after reviving a part of the dried specimens in $10 \% \mathrm{KOH}$ solution and staining the sections in $1 \%$ Cotton blue or $2 \%$ Congo red. The Line drawings of microscopic details were drawn with the aid of Camera Lucida under oil lens. The magnification of each drawing has been mentioned at appropriate place on the plate of individual taxon. All the examined collections have been deposited in the Herbarium of Botany Department, Punjabi University, Patiala, Punjab, India under PUN. The authentic names, basionym and synonyms of the investigated taxa are as per the latest version of Dictionary of Fungi by Kirk et al. (2008) and the information available on MycoBank (www.mycobank.org).

\section{Key to the investigated coprophilous species of Conocybe}

1 Stipe cuticle mainly consisting of lecythiform caulocystidia; non-lecythiform caulocystidia absent or very rarely present; pseudoparaphyses absent in the hymenophore $\ldots \ldots \ldots \ldots \ldots \ldots \ldots \ldots \ldots \ldots . .2$ 1' Stipe cuticle consists of a mixture of lecythiform and non-lecythiform caulocystidia or only nonlecythiform caulocystidia; pseudoparaphyses absent or present between basidia in the

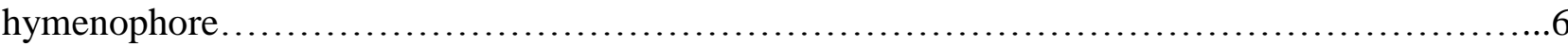


2 Pileocystidia present; stipe equal in diameter throughout...................................

2' Pileocystidia absent; stipe base obclavate..................................................

3 Ammonia reaction positive, long, needle-shaped crystals are produced in ammonical mounts of the lamellae; pileus reddish brown when young, brownish yellow with reddish brown apex at maturity; lamellae adnate, subdistant; basidiospores $8.5-10.7 \times 5.7-6.4 \mu \mathrm{m}$............ . brachypodii 3' Ammonia reaction negative.

4 Pileus reddish golden when young, light brown at maturity, smooth, umbonate; lamellae distant; caulocystidia exclusively lecythiform.

C. subxerophytica var. subxerophytica

4' Pileus yellowish brown to dark brown, radially wrinkled, ex-umbonate; lamellae subdistant; caulocystidia mainly lecythiform, but mixed with few non-lecythiform

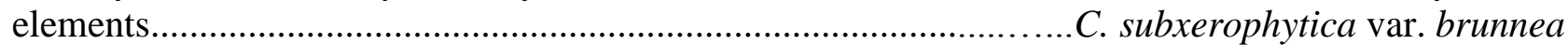
5 Lamellae adnexed, 3-sized; stipe surface white, brownish when handled; basidiospores 12-15 $\times$

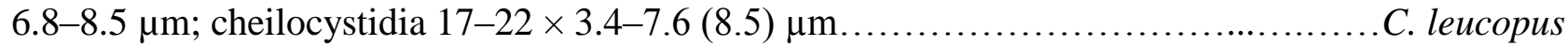
5' Lamellae adnate, 2-sized; stipe surface yellowish white, unchanging; basidiospores 8.5-12 $\times 5-7$

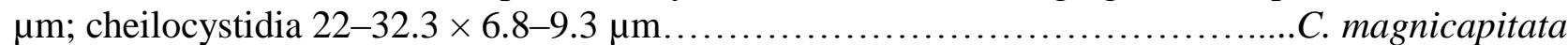

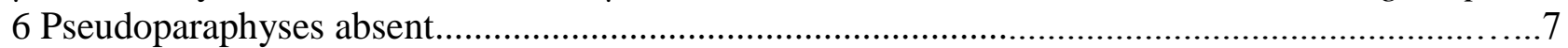

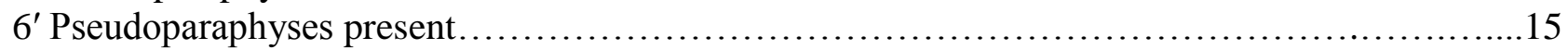

7 Caulocystidia mixed, both lecythiform and non-lecythiform ............................... 8

7' Caulocystidia exclusively non-lecythiform................................................

8 Pileus $3-3.3 \mathrm{~cm}$ broad, campanulate to conico-convex, with an elongated brown umbo, surface yellowish brown with lighter margin, bruising brown; basidia 4-spored.............. . subpubescens 8' Pileus 1-1.4 cm broad, conical, with slightly raised apex, surface reddish brown; basidia 2-, 3and 4-spored.

C. uralensis

9 Stipe tubular, base elongated to form a pseudorrhiza; pileus surface yellowish brown having white shades, with small point like brown umbo; basidia 2- and 4-spored; basidiospores 10-12.7 $\times$ 6.8-8.5 $\mu \mathrm{m}$, limoniform-subhexagonal in face view, ellipsoidal in side view; lecythiform pileocystidia present............................................ microrrhiza var. coprophila 9' Stipe with equal or bulbous base, pseudorrhiza absent; pileocystidia present or absent...............................................................................

10 Carpophores 6-16 cm in height; pileus surface pale white, pale gray along the periphery, conical with elongated yellowish brown umbo, pileal margin striate-plicate, with radiating ridges and grooves extending up to the apex; stipe with distinctly bulbous base; basidiospores $10-17 \times 7.6-10$ $\mu \mathrm{m}$; clamp connections absent throughout............................................. apala $10^{\prime}$ Pileus conical to campanulate, pileal margin never plicate, never with ridges and grooves; clamp connections present in stipe context hyphae........................................... 11

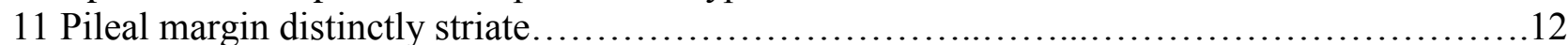

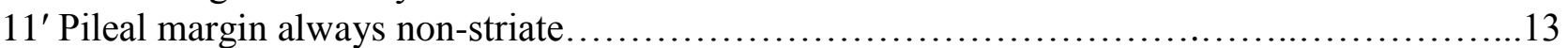

12 Pileus surface grayish white to pale gray, grayish brown at maturity, $1.2-1.3 \mathrm{~cm}$ broad; lamellae adnate; stipe cylindrical; pileocystidia absent; caulocystidia sometimes with loops at the apex............................................................................... moseri $12^{\prime}$ Pileus surface brownish orange when young, grayish yellow, 1.7-2.4 cm broad; lamellae adnexed; stipe with bulbous base; pileocystidia present; caulocystidia without

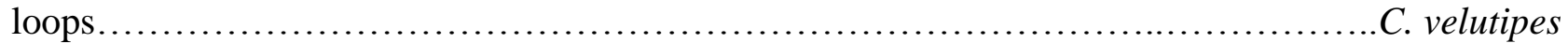

13 Pileus umbonate, surface yellowish brown, dark brown towards the margin; basidia 4-spored; basidiospores $10-12.8(13.5) \times 5.7-7 \mu \mathrm{m}$, lentiform in face view................... lenticulospora 13 ' Pileus ex-umbonate; basidia 2 - and 4 -spored............................................ 14 Pileus beige, creamish when young, reddish brown at maturity; pileocystidia absent; basidia

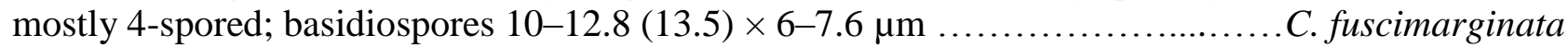
14 ' Pileus yellowish brown; pileocystidia present, sometimes with loops at the apex; basidia mostly

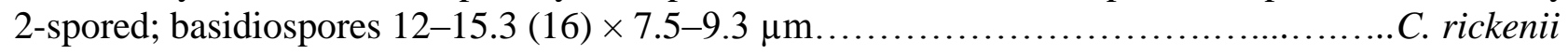
15 Pileus conical, ex-umbonate, with non-striate margin, surface pale to light creamish when young, yellowish brown at maturity; lamellae adnate, with hard and wrinkled edges at maturity; 
stipe $0.2-0.3 \mathrm{~cm}$ broad; basidia mostly 2 -spored. C. crispa

15' Pileus conical to convex, umbonate, with striate, sometimes reflexed margin, surface white; lamellae adnexed to free, with smooth edges; stipe $0.3-0.5 \mathrm{~cm}$ broad; basidia 4-spored.....C. albipes

\section{Taxonomic Descriptions}

1. Conocybe brachypodii (Velen.) Hauskn. \& Svrček in Czech Mycol. 51: 43, 1999.

\subsection{Basionym - Galera brachypodii Velen. in Novit. Mycol. 67, 1947.}

1.2. Synonyms - Conocybe excedens Kühner \& Watling in Notes Roy. Bot. Gdn. Edinb. 40: 537, 1983.

Conocybe excedens var. pseudomesospora Singer \& Hauskn. in Pl. Syst. Evol. 180: 95, 1992.

Conocybe macrocephala var. riedheimensis Hauskn. \& Enderlé in Österr. Z. Pilzk. 9: 95, 2000.

1.3. Chemical Reaction - Ammonia reaction positive, needle-shaped crystals are formed in ammonical mounts of lamellae.

1.4. Material Examined - India, North India, Punjab, Patiala, Mehmoodpur Jattan, 251m asl, growing in groups on cattle dung heap, Amandeep Kaur, 14 June 2008, PUN 3899.

1.5. Discussion - Conocybe brachypodii belongs to section Conocybe Singer of series Mesospora Hauskn. \& Krisai (Hausknecht \& Krisai 2006). It is identified by conico-convex to fan-shaped pileus with moist, delicate, hygrophanous surface and non-striate margin; adnate, subdistant lamellae; stipe surface yellowish white which bruises brown near the base; basidiospores 8.5-10.7 $\times$ 5.7-6.4 $\mu \mathrm{m}$ in size; mostly 4-spored basidia; stipe cuticle with exclusively lecythiform caulocystidia; clamp connections present throughout and ammonia reaction positive which shows long needle shaped crystals in ammonical mounts of gill tissue. Conocybe mesospora Kühner \& Watling is a closely related species but differs in having smaller basidiospores $(7.5-10 \times 4.5-5 \mu \mathrm{m})$, distinctly striate pileal margin, fibrillose stipe and negative ammonia reaction (Watling 1982, Prydiuk 2007b). Another species which resembles to it in its gross external and internal details is $C$. macrocephala (Kühner) Kühner \& Watling but differs in having prominently umbonate pileus with its margin striate to half way, crowded gills and bulbous stipe with longitudinal striations at the apex. In comparison the presently examined collection possesses exumbonate pileus without striations in the pileus and stipe, subdistant gills and tubular, hollow stipe without bulbous base.

This fungus is reported to be common in Europe, growing as a saprobe on dung, woods, or in grassy areas (Hausknecht 2002, Arnolds 2005). It was also reported growing on soil in deciduous forests (Prydiuk 2007b). Atri et al. (2009) reported it as a new record from India.

2. Conocybe subxerophytica var. subxerophytica Singer \& Hauskn. in Pl. Syst. Evol. 213: 98, 1992.

2.1. Material Examined - India, Punjab, Patiala Samana, $251 \mathrm{~m}$ asl, growing scattered on buffalo dung, Amandeep Kaur, 25 June 2008, PUN 4216.

2.2. Discussion - This species belong to section Conocybe Singer and series Tenera Hauskn. and Krisai (Hausknecht \& Krisai 2006). It is recognized by the presence of exclusively lecythiform caulocystidia, light brown pileus, stipe bruising brown and negative ammonia reaction (Hausknecht et al. 2009).Hausknecht et al. (2009) documented this species growing in sandy or gravelly soil from the dry meadows of Siberia. It has been reported as new record from India by Atri et al. (2012). 
3.1. Material Examined - India, Punjab, Barnala, Sherpur, $228 \mathrm{~m}$ asl, growing in groups on horse dung, Amandeep Kaur, 13 July 2008, PUN 4217.

3.2. Discussion - This species fall under section Conocybe Singer and series Tenera Hauskn. \& Krisai (Hausknecht \& Krisai 2006). In view of the yellowish brown to dark brown, radially wrinkled pileus, more closely aggregated lamellae in comparison to $C$. subxerophytica var. subxerophytica, and the presence of mainly lecythiform caulocystidia along with some nonlecythiform elements interspersed on the stipe surface, this collection has been identified as $C$. subxerophytica var. brunnea Hauskn. All its macroscopic and microscopic details are in conformity with the details given by Prydiuk (2007b) for this taxon which is reported growing on soil from Ukraine. Atri et al. (2012) has reported it as new record from India.

4. Conocybe leucopus (Kühner) Kühner \& Watling in Notes from the Royal Botanic Garden Edinburgh 40 (3): 539, 1983.

Figs. 1-2

4.1. Macroscopic Features - Carpophores 3.4-6.5 cm in height. Pileus 1.5-2.6 cm broad, conical to convex; umbonate, umbo small, pointed, brown; surface yellowish white, dry, slightly wrinkled at maturity; margin regular, splitting at maturity, non-striate, pale yellow; cuticle not peeling; flesh thin, up to $0.15 \mathrm{~cm}$ thick, yellowish white, unchanging; pileal veil absent; taste and odor not distinctive. Lamellae adnexed, unequal, 3-sized, subdistant, narrow, $0.15-0.2 \mathrm{~cm}$ broad in the center, yellowish brown to orange brown; gill edges smooth to wavy near the margin, white. Spore print brownish orange $\left(6 \mathrm{C}_{4}\right)$. Stipe $3.1-6.3 \mathrm{~cm}$ long, $0.2-0.3 \mathrm{~cm}$ broad, tubular, obclavate, not rooting, slightly curved, hollow, surface pure white, brownish when handled, pruinose, longitudinally striate.

4.2. Microscopic Features - Basidiospores 12-15 × 6.8-8.5 $\mu \mathrm{m}(\mathrm{Q}=1.76)$, elongated ellipsoidal, with a broad germ pore, thick-walled, smooth, golden yellow. Basidia 15.3-24.6 × 7.6-10 $\mu$ m, clavate, 4- spored, thin walled, hyaline; sterigmata 1.7-3.4 $\mu \mathrm{m}$ long. Pseudoparaphyses absent. Gill edges heteromerous. Cheilocystidia 17-22 × 3.4-7.6 (8.5) $\mu \mathrm{m}$, lecythiform, with well differentiated tapered neck, thin-walled, hyaline; capitellum 2.5-4.3 $\mu \mathrm{m}$ broad. Pleurocystidia absent. Pileus cuticle a hymeniform layer; cellular elements 17.8-39 × 10-18.7 $\mu \mathrm{m}$, ellipsoidal, pyriform to pedicellate clavate, thin walled, hyaline; pileocystidia absent; pileus context homoiomerous, composed of 5-12 $\mu \mathrm{m}$ broad hyphae. Hymenophoral trama regular, made up of parallel, thin walled, hyaline 5-14.5 $\mu \mathrm{m}$ broad hyphae. Subhymenium pseudoparenchymatous. Stipe cuticle hyphal with caulocystidia forming scattered tufts without any intermixed filamentous hairs; caulocystidia 15.3-22 × 4.3-6.8 $\mu \mathrm{m}$, lecythiform, thin-walled, hyaline, capitellum 3.4-5 $\mu \mathrm{m}$ broad; stipe context made up of longitudinally parallel thin-walled hyaline 4.3-12.7 $\mu \mathrm{m}$ broad hyphae. Clamp connections present in stipe context hyphae.

4.3. Chemical Reaction - Ammonia reaction negative, crystals are not formed in ammonical mounts of lamellae.

4.4. Material Examined - India, Punjab, Ferozepur, Mudki, $182 \mathrm{~m}$ asl, growing scattered in a group on cow dung on ants' excreta, Amandeep Kaur, 16 August 2011, PUN 4800.

4.5. Discussion - The presently examined collection belongs to section Conocybe Singer and series Leucopus Hauskn. \& Krisai (Hausknecht \& Krisai 2006). It has been identified as C. leucopus and can be recognized by yellowish white pileus with brown center and white stipe, non-striate pileal margin and the presence of lecythiform cystidia on the stipe surface and the pileal margin. Conocybe semiglobata is closely related to this species but can be differentiated by the formation of 
needle-shaped crystals in ammonical mounts of lamellae and by the stipe which is never white.

Watling (1982) reported the species growing on sandy or clayey soils containing little or no organic matter, in gardens, and on pathsides from British Isles. Gerault (2005) recorded it growing on clayey soils and in gardens. Presently it has been recorded growing scattered in a group on cow dung for the first time from India.
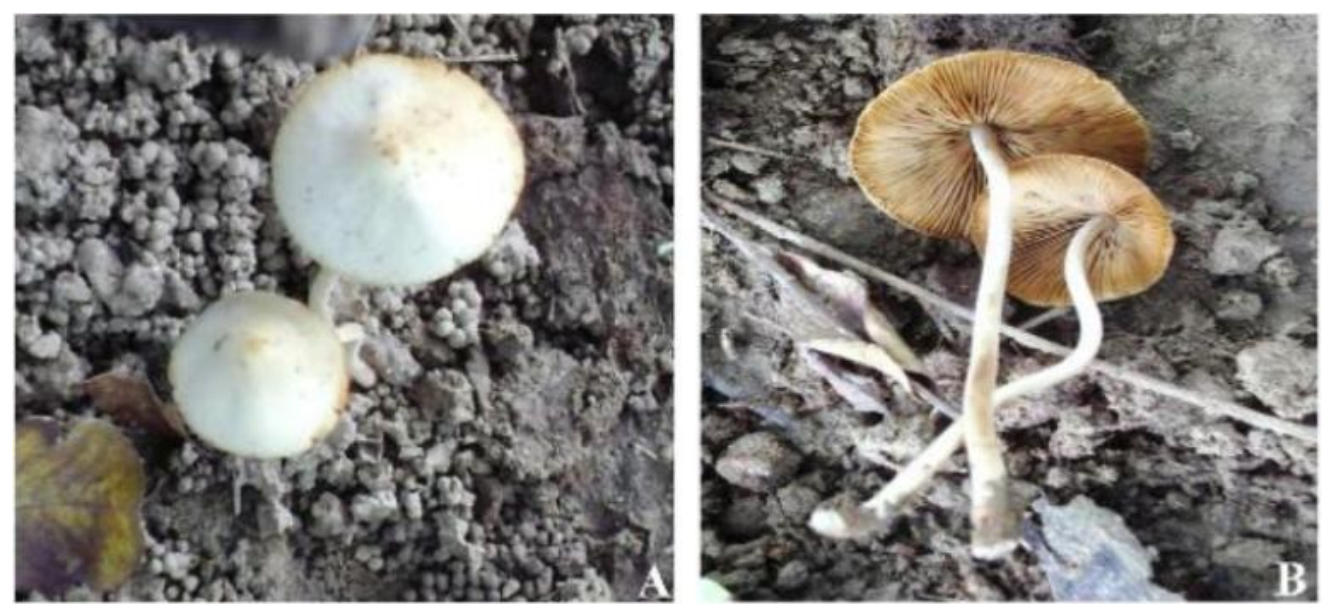

Fig. 1 - Conocybe leucopus. A. Carpophores growing in natural habitat; B. Undersurface of the pileus showing subdistant and narrow lamellae.
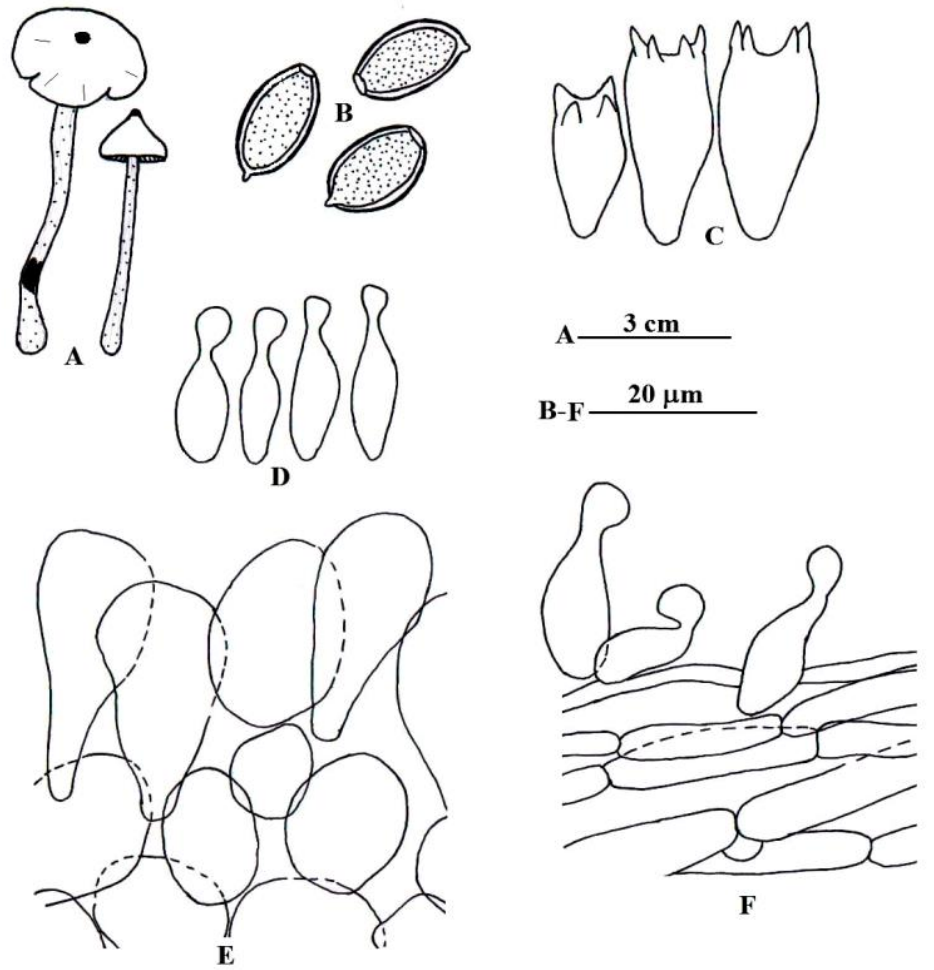

Fig. 2 - Conocybe leucopus. A. Carpophores; B. Basidiospores; C. Basidia; D. Cheilocystidia; E. Pileal elements; F. Caulocystidia on the stipe surface.

5. Conocybe magnicapitata P. D. Orton in Trans. Brit. Mycol. Soc. 43 (2): 193, $1960 . \quad$ Figs. 3-4

5.1. Synonyms - Conocybe spicula f. macrospora Kühner in Le Genre Galera 63, 1935.

Galera tenera f. minor J. Lange in Dansk. Bot. Arkiv 9 (6): 37, 1938.

Conocybe juniana (Velen.) Hauskn. \& Svrček in Österr. Z. Pilzk. 8: 46, 1999. 
5.2. Macroscopic Features- Carpophore up to $7.5 \mathrm{~cm}$ in height. Pileus up to $2.4 \mathrm{~cm}$ broad, $1.4 \mathrm{~cm}$ high, conico-convex; umbonate, umbo small, acute, yellowish brown; surface yellowish white, with pale yellow $\left(4 \mathrm{~A}_{3}\right)$ shades, dry, rugulose; margin regular, not splitting, slightly striate, involute; cuticle not peeling; flesh thin, up to $0.15 \mathrm{~cm}$ thick, yellowish white, unchanging; pileal veil absent; taste and odor not distinctive. Lamellae adnate, unequal, 2-sized, subdistant, narrow, up to $0.2 \mathrm{~cm}$ broad, yellowish brown; gill edges smooth to denticulate near the margin. Spore print yellowish brown. Stipe central, $7.4 \mathrm{~cm}$ long, $0.35 \mathrm{~cm}$ broad, cylindrical, obclavate, hollow, surface yellowish white, pruinose, longitudinally striate; annulus absent.

5.3. Microscopic Features - Basidiospores 8.5-12 $\times 5-7 \mu \mathrm{m}(\mathrm{Q}=1.7)$, ellipsoidal, with truncate germ pore, thick-walled, smooth, rusty yellow in water, rusty brown in $\mathrm{KOH}$. Basidia 18.7-25.5 $\times$ 10-12 $\mu \mathrm{m}$, clavate, 4-spored, thin walled, granular; sterigmata 2.5-4.3 $\mu \mathrm{m}$ long. Pseudoparaphyses absent. Gill edges sterile. Cheilocystidia 22-32.3 × 6.8-9.3 $\mu \mathrm{m}$, lecythiform, thin-walled, hyaline; capitellum 3.4-6 $\mu \mathrm{m}$ broad. Pleurocystidia absent. Pileus cuticle hymeniform, made up of 17-37.4 $\times 18.7-32.3 \mu \mathrm{m}$, globose or even subglobose to clavate, thin walled, hyaline cellular elements; pileocystidia absent; pileus context homoiomerous, composed of 5-12.7 $\mu \mathrm{m}$ broad hyphae. Hymenophoral trama regular, made up of parallel, thin walled, hyaline 3.4-10 $\mu \mathrm{m}$ broad hyphae. Subhymenium pseudoparenchymatous. Stipe cuticle hyphal with caulocystidia scattered in groups; caulocystidia 17-27.2 × 4.3-7.6 $\mu \mathrm{m}$, lecythiform, thin-walled, hyaline, capitellum 3.4-4.3 $\mu \mathrm{m}$ broad; stipe context made up of longitudinally running, thin-walled hyaline $6-22 \mu \mathrm{m}$ broad hyphae. Clamp connections present in the stipe context hyphae.

\subsection{Chemical Reaction - Ammonia reaction negative.}

5.5. Material Examined - India, Punjab, Ferozepur, Sodhinagar, $182 \mathrm{~m}$ asl, growing solitary on buffalo dung, Amandeep Kaur, 16 August 2011, PUN 4801.

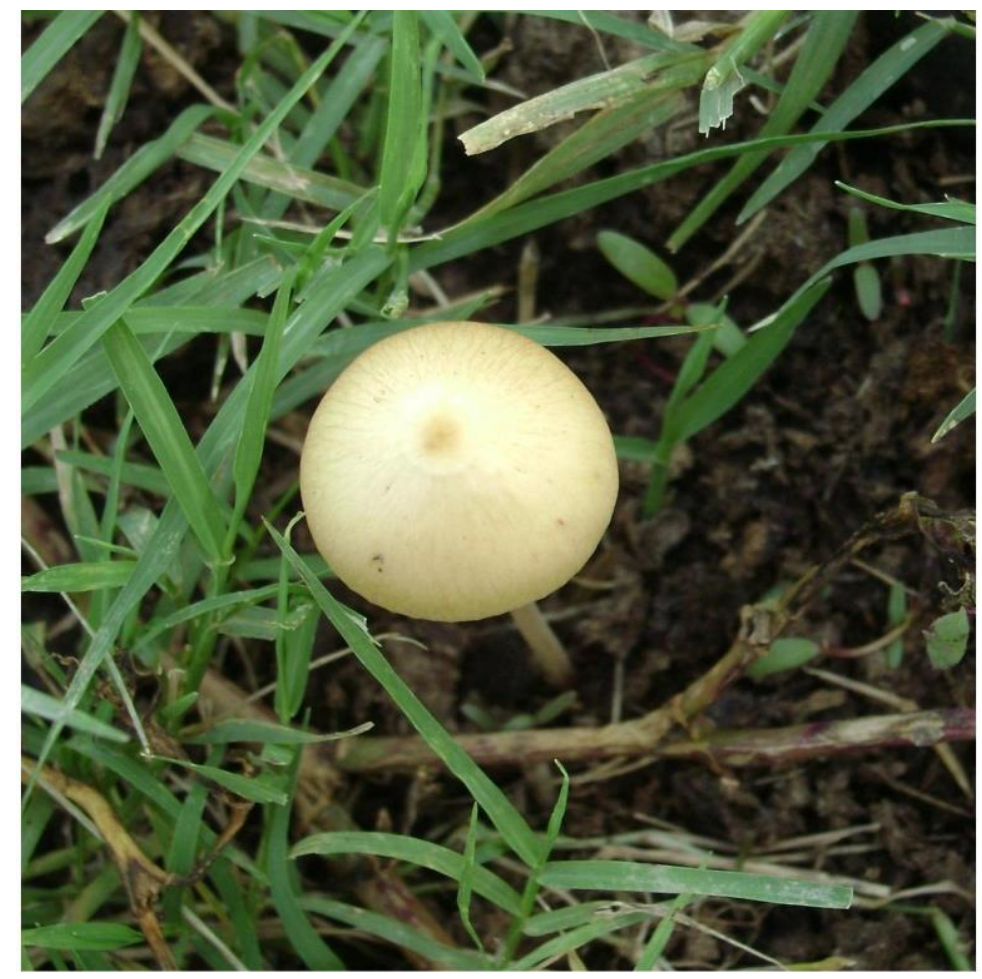

Fig. 3 - Conocybe magnicapitata. Carpophore growing in natural habitat. 


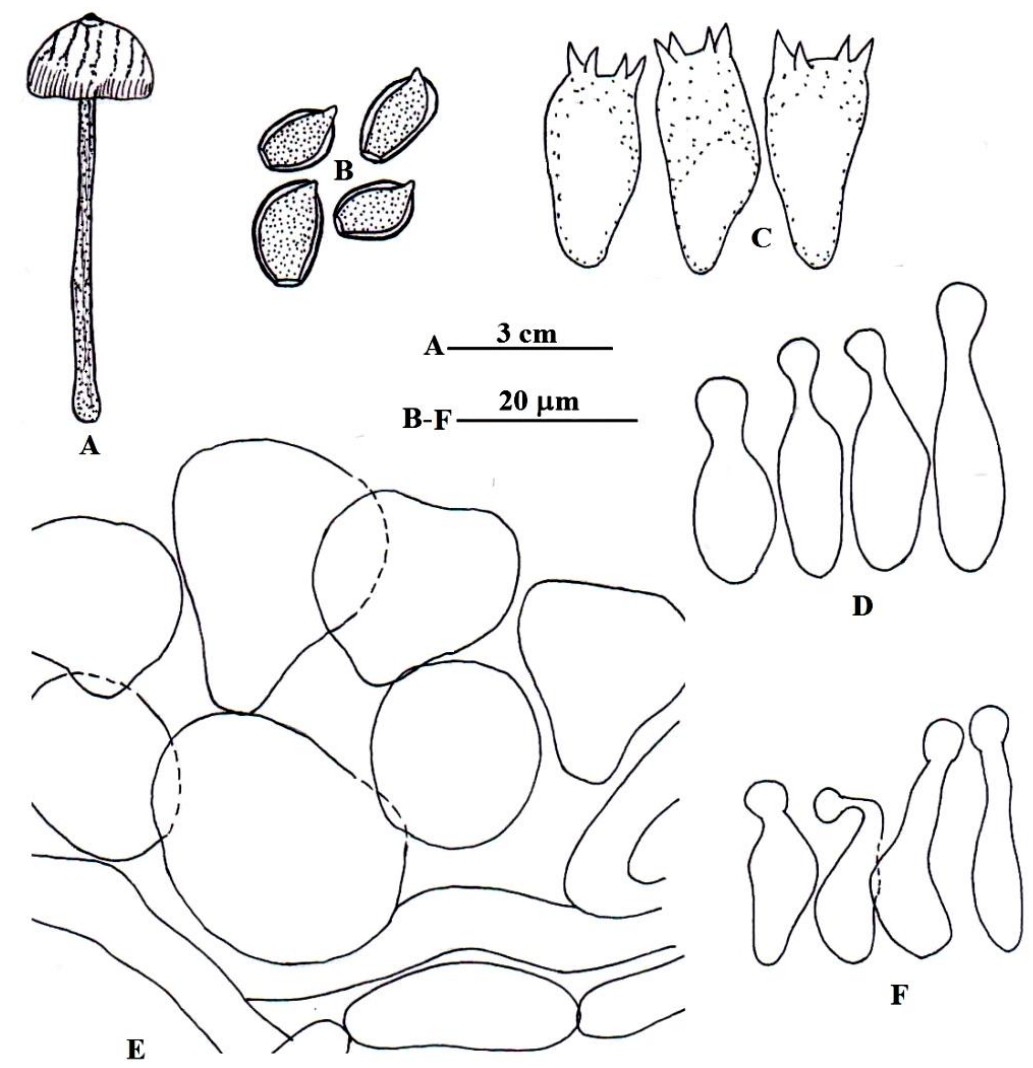

Fig. 4 - Conocybe magnicapitata. A. Carpophore; B. Basidiospores; C. Basidia; D. Cheilocystidia; E.Pileal elements; F. Caulocystidia.

5.6. Discussion - The above examined collection fall under section Conocybe Singer and series Magnicapitatu Hauskn. \& Krisai (Hausknecht \& Krisai 2006). The macroscopic and microscopic details of this specimen are in conformity with those given for C. magnicapitata by Watling (1982). It is recognized by the medium sized carpophores, conico-convex pileus, slightly striate pileal margin and stipe cuticle covered with large-headed lecythiform caulocystidia. $C$. tenera is quite close to it but differs in larger sized and much brighter colored carpophores and distinctly striate pileal margin (Watling 1982).

The species has been reported growing on soil in woods or fields and in bare areas from British Isles (Watling 1982). Earlier C. magnicapitata was documented by Watling and Gregory (1980) from Kashmir. It is recorded growing solitary on buffalo dung for the first time from Punjab.

6. Conocybe subpubescens P. D. Orton in Trans. of British Mycol. Soc., 43: 195, 1960.

Figs. 5-6

6.1. Synonyms - Conocybe pubescens (Gillet) Kühner sensu Kühner 1935. Conocybe digitalina (Velen.) Singer 1989.

6.2. Macroscopic Features - Carpophores $6.2-6.5 \mathrm{~cm}$ in height; Pileus $3-3.3 \mathrm{~cm}$ broad, $1.5-1.8 \mathrm{~cm}$ high, campanulate to conico-convex; umbonate, umbo elongated, broad, brown $\left(6 \mathrm{E}_{7}\right)$; surface dry, delicate, yellowish brown $\left(5 \mathrm{E}_{8}\right)$ with lighter margin, changing to brown on bruising, smooth; margin irregular, reflexed, splitting at maturity, non-striate; cuticle not peeling; flesh thin, yellowish white, unchanging; pileal veil absent; taste and odor not distinctive. Lamellae adnate, unequal, 2-sized, subdistant, moderately broad $(0.25 \mathrm{~cm})$, yellowish brown $\left(5 \mathrm{E}_{8}\right)$, gill edges smooth, fragile. Spore print brown $\left(6 \mathrm{E}_{8}\right)$. Stipe central, $6-6.3 \mathrm{~cm}$ long, $0.2-0.25 \mathrm{~cm}$ broad, cylindrical, with distinctly bulbous base, hollow, surface white $\left(2 \mathrm{~A}_{1}\right)$ to light cream, bruising brown, fibrillose. 


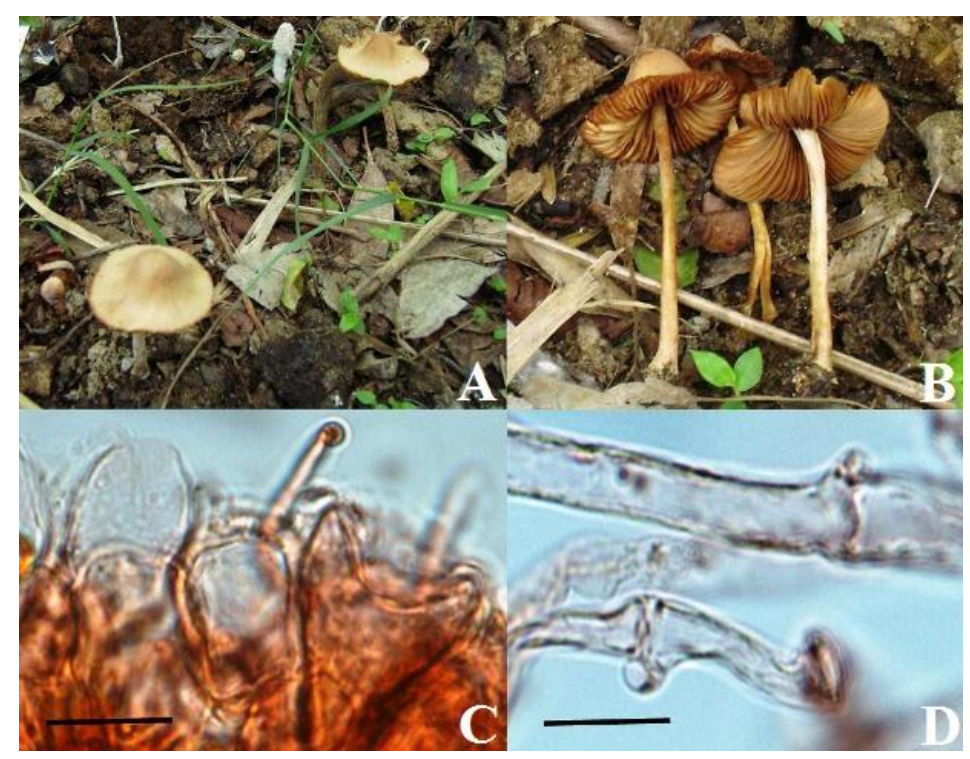

Fig. 5 - Conocybe subpubescens. A. Carpophores growing scattered in natural habitat; B. Pileal undersurface showing subdistant lamellae; C. Pileus cuticle elements; D. Stipe context hyphae showing clamp connections. Bars C-D $10 \mu \mathrm{m}$
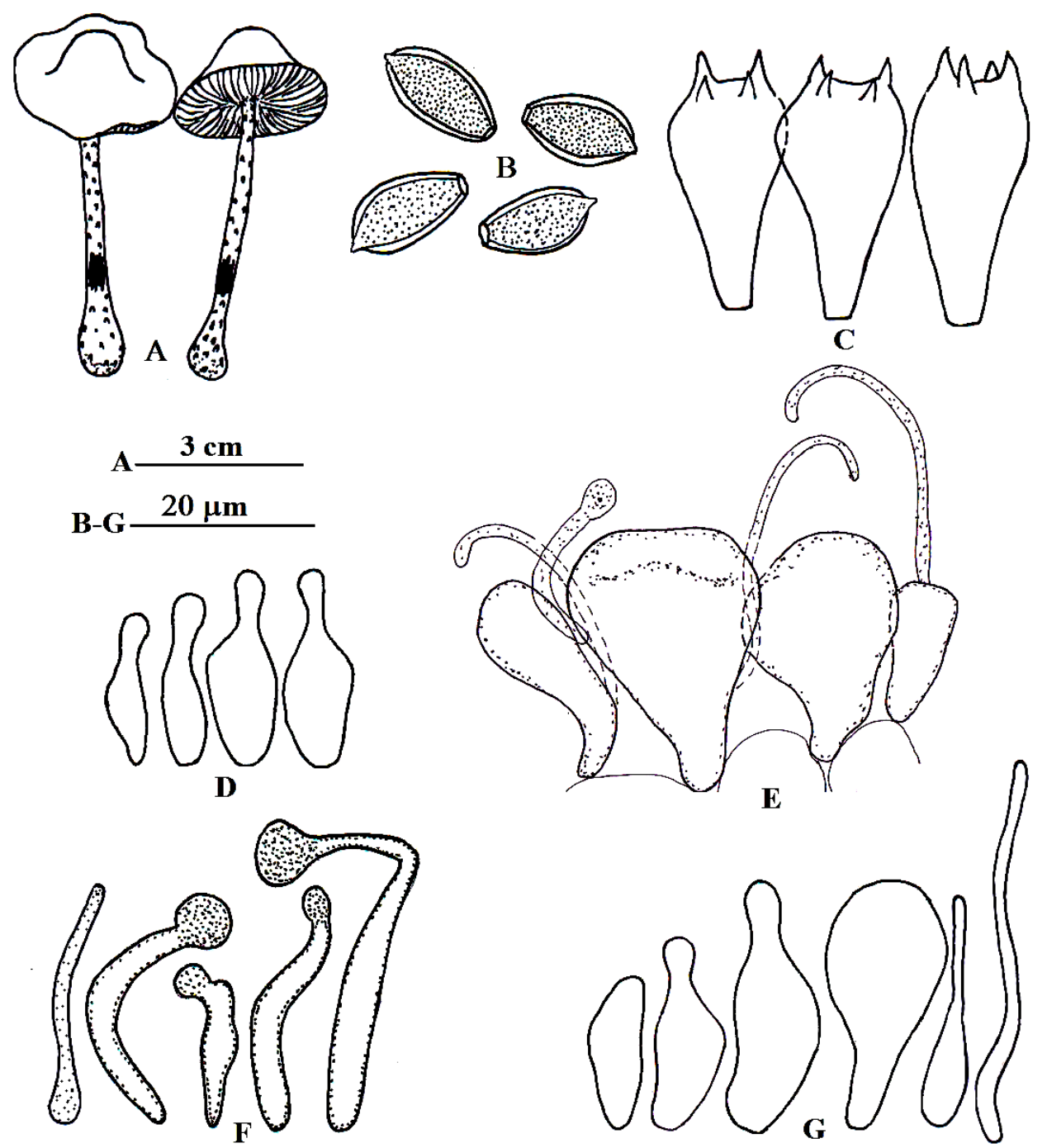

Fig. 6 - Conocybe subpubescens. A. Carpophores; B. Basidiospores; C. Basidia; D. Cheilocystidia; E. Pileal elements; F. Pileocystidia; G. Caulocystidia. 
6.3. Microscopic Features - Basidiospores 12-13.6(14.2) × 6-7.8 $\mu \mathrm{m}(\mathrm{Q}=1.85)$, elongated ellipsoidal, with truncate germ pore, thick-walled, smooth, yellowish brown in water, rusty brown in $\mathrm{KOH}$. Basidia 20.4-29 × 10-13.6 $\mu \mathrm{m}$, cylindrico-clavate to clavate, 4-spored, thin-walled, hyaline; sterigmata 3.4-4.3 $\mu \mathrm{m}$ long. Pseudoparaphyses absent. Gill edges sterile. Cheilocystidia 13.6-20.4 $\times$ 4.3-7.6 $\mu \mathrm{m}$, lecythiform, thin-walled, hyaline; capitellum 1.7-3.4 $\mu \mathrm{m}$ broad. Pleurocystidia absent. Pileus cuticle hymeniform with scattered pileocystidia; composed of 18.7-40 $\times 8.5-27.2 \mu \mathrm{m}$, polymorphic, cylindrico-clavate, inflated clavate or spheropedunculate, thin-walled, hyaline cells; pileocystidia 18.7-59.5 $\times 2.5-13.7 \mu \mathrm{m}$, polymorphic, filamentous, twisted, curved, wavy to obclavate, with 1.7-6 $\mu \mathrm{m}$ broad capitellum; pileus context hyphae intermingled, thin walled, hyaline, 6.8-22 $\mu \mathrm{m}$ broad. Hymenophoral trama regular, made up of thin walled, hyaline 5$17 \mu \mathrm{m}$ broad hyphae. Stipe cuticle having mixed lecythiform and non-lecythiform caulocystidia scattered in groups; stipe context hyphae longitudinally parallel, thin-walled, hyaline 6.8-30.6 $\mu \mathrm{m}$ broad; caulocystidia 13.6-34 × 4.3-15.3 $\mu \mathrm{m}$, lecythiform, hairy, clavate, obclavate to lageniform, thin-walled, hyaline. Clamp connections present in stipe context hyphae and basal mycelium.

\subsection{Chemical Reaction - Ammonia reaction negative.}

6.5. Material Examined - India, Punjab, Hoshiarpur, Jalota Dasuya, $295 \mathrm{~m}$ asl, growing scattered in a group on mixed horse dung and cattle dung heap mixed with leaf litter, Amandeep Kaur, 14 July 2010, PUN 4348.

6.6. Discussion - The above examined collection belongs to section Mixtae Singer and subsection Pubescens Hauskn. \& Krisai (Hausknecht \& Krisai 2006). It has been identified as $C$. subpubescens. All its macroscopic and microscopic details are in conformity with those given for this species by Watling (1982) and Prydiuk (2007a). Conocybe subpubescens is distinctive by its spore size, pubescent stipe, campanulate unexpanding pileus and stipe cuticle with lecythiform and non-lecythiform caulocystidia mixed with hairs (Hausknecht et al. 2009). Conocybe pubescens (Gillet) Kühner differs from it in having larger spore size (14-17.5 (22) × 7-9 (10) $\mu \mathrm{m})$, deep sienna to ochre pileus and growth directly on dung (Watling 1982; Watling and Bigelow 1983). Conocybe farinacea Watling is quite close species which can be differentiated by the strong farinaceous smell and taste and broader basidiospores.

Watling (1982) reported $C$. subpubescens growing in woods, and in damp places from British Isles. Watling and Bigelow (1983) reported this species growing on dung-soil mixtures, on soil, dead grass leaves and accumulations of leaves of deciduous trees and shrubs in moist areas. They collected three specimens growing on fertilized soil in greenhouse from Massachusetts during the month of February and April. The species has also been reported by Kaşik et al. (2004) from Turkey, Arnolds (2005) from Europe and Hausknecht et al. (2009) from Russia and Georgia. Prydiuk (2007a) reported the species growing on soil among grass on roadside from Ukraine. Presently it has been recorded growing scattered on mixed horse and cattle dung heap along with leaf litter for the first time from India.

7. Conocybe uralensis Hauskn, Knudsen \& Mukhin in Folia Cryptog. Estonica, Fasc. 45: 33, 2009.

7.1. Material Examined - India, Punjab, Ropar, Kuraali, $394 \mathrm{~m}$ asl, growing in groups on buffalo dung heap, Amandeep Kaur, 21 August 2009, PUN 4218.

7.2. Discussion - This species belongs to section Mixtae Singer and subsection Ambiguae Hauskn. \& Krisai as it possess mycenoid basidiocarps, non-radicant stipe base, limoniform spores, lecythiform or capilliform pileocystidia and stipe cuticle with a mixture of lecythiform and nonlecythiform elements (Hausknecht \& Krisai 2006). It is recognized by the presence of 4-spored 
basidia mixed with a few 2- or 3-spored basidia, non-angular spores with distinct germ pore and pileocystidia and caulocystidia having moist and slimy capitellum (Hausknecht et al. 2009). Conocybe ambigua is quite close which differs from this species by having exclusively 2-spored basidia with prominent, tapered sterigmata and distinctly amygdaliform basidiospores (Watling 1982). Conocybe pseudopilosella is another species which is close to it but that differs by having conico-convex to campanulate pileus, adnate lamellae with flocculose edges, pilose-striate stipe with whitish tomentum at the base (Watling 1982).

Hausknecht et al. (2009) reported $C$. uralensis from Russia growing among mosses on clayey and sandy soil.

8. Conocybe microrrhiza Hauskn. var. coprophila Amandeep Kaur, Atri and Munruchi Kaur var. nov.

Fig. 7

\subsection{MycoBank No. - MB 808595}

8.2. Etymology - The mushroom is named so for its radicant stipe and coprophilous habitat.

8.3. Macroscopic Features - Carpophore $6 \mathrm{~cm}$ in height (excluding pseudorrhiza). Pileus $1.4 \mathrm{~cm}$ broad, $0.9 \mathrm{~cm}$ high, conico-convex; umbonate, umbo small, point like, brown; surface yellowish brown with white shades, dry; margin regular, not splitting, non-striate; cuticle not peeling; flesh thin, up to $0.15 \mathrm{~cm}$ thick, pale white, unchanging; pileal veil absent; taste and odor not distinctive. Lamellae adnexed, unequal, 2-sized, subdistant, moderately broad, up to $0.25 \mathrm{~cm}$ broad, fragile, yellowish brown; gill edges smooth. Stipe central, $5.9 \mathrm{~cm}$ long, $0.15 \mathrm{~cm}$ broad, tubular, with rootlike, $2 \mathrm{~cm}$ long pseudorrhiza, hollow, surface yellowish brown, pruinose.

8.4. Microscopic Features - Basidiospores 10-12.7 × 6.8-8.5 $\mu \mathrm{m}(\mathrm{Q}=1.48)$, limoniformsubhexagonal in face view, ellipsoidal in side view, truncated by a central germ pore, thick-walled, smooth, rusty yellow. Basidia 15.3-25.5 × 8.5-12 $\mu \mathrm{m}$, clavate, 2- and 4-spored, thin walled, hyaline; sterigmata 3.4-4.3 $\mu \mathrm{m}$ long. Pseudoparaphyses absent. Gill edges sterile. Cheilocystidia 15.3-25.5 × 5-7.6 $\mu \mathrm{m}$, lecythiform, thin-walled, hyaline; capitellum 2.5-3.4 $\mu \mathrm{m}$ broad. Pleurocystidia absent. Pileus cuticle hymeniform with scattered pileocystidia, cellular elements 15.3-35.7 $\times 12.7-22 \mu \mathrm{m}$, ellipsoidal, pyriform to clavate, thin walled, hyaline; pileocystidia 22$42.5 \times 3.5-8.5 \mu \mathrm{m}$, lecythiform, thin-walled, granular; capitellum 1.7-4.3 $\mu \mathrm{m}$ broad; pileus context homoiomerous, composed of interwoven, thin walled, hyaline 5-15.3 $\mu \mathrm{m}$ broad hyphae. Hymenophoral trama regular, made up of parallel, thin walled, hyaline 3.4-12 $\mu \mathrm{m}$ broad hyphae. Subhymenium pseudoparenchymatous. Stipe cuticle hyphal covered by non-lecythiform caulocystidia and filamentous hairs; caulocystidia 15.3-29 $\times$ 5-9.3 $\mu \mathrm{m}$, cylindrical, clavate to sublageniform, thin-walled, hyaline; stipe context composed of thin-walled, hyaline 5-35.7 $\mu \mathrm{m}$ broad hyphae. Clamp connections present in stipe context hyphae.

8.5. Chemical Reaction - Ammonia reaction negative.

8.6. Material Examined - India, Punjab, Faridkot, Chandwaja, $196 \mathrm{~m}$ asl, growing solitary on cow dung, Amandeep Kaur, 19 August 2011, PUN 4802.

8.7. Discussion - The presently examined species belongs to section Pilosellae Singer as it possesses non-lecythiform caulocystidia and capilliform or lecythiform pileocystidia and series Microrrhiza Hauskn. \& Krisai as its stipe is radicant and stipe base not bulbous (Hausknecht \& Krisai 2006). It has been named as $C$. microrrhiza var. coprophila. var. nov. It is distinctive in possessing conico-convex pileus with point like umbo, 4-spored basidia along with 2-spored, lecythiform pileocystidia scattered between pileus cuticle cells and growth on dung. Conocybe leporina also has a rooting stipe and coprophilous habitat (rabbit droppings) but differs in 


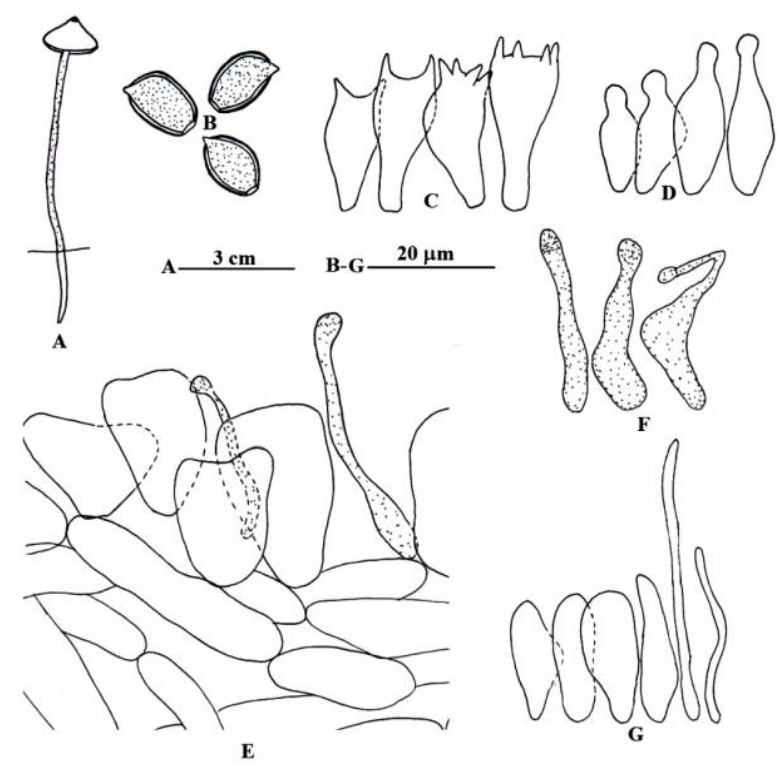

Fig. 7 - Conocybe microrrhiza var. coprophila. A. Carpophore; B. Basidiospores; C. Basidia; D. Cheilocystidia; E. Pileus cuticle elements; F. Pileocystidia G. Caulocystidia.

possessing 2-spored basidia and narrower (5-6.5 (8) $\mu \mathrm{m}$ broad) spores (Prydiuk 2007a, Gerault 2005). Conocybe microrrhiza var. microrrhiza Hauskn. is similar to the presently examined collection in external morphology and spore size, but differs by the presence of only 2-spored basidia, absence of pileocystidia and growth on sandy soil (Prydiuk 2007a). Other varieties of this species, C. microrrhiza var. tetraspora and C. microrrhiza var. parvispora have only 4-spored basidia and smaller spores (Prydiuk 2007a). In view of these significant differences, a new variety Conocybe microrrhiza var. coprophila has been proposed to accommodate the above examined collection. Presently C. microrrhiza has been documented for the first time from India.

9. Conocybe apala (Fr.) Arnolds in Persoonia 18(2): 225, 2003.

Fig. 8 9.1. Materials Examined - India, Punjab, Tarn Taran, Baath, $169 \mathrm{~m}$ asl, growing solitary on buffalo dung, Amandeep Kaur, 31 July 2010, PUN 4219; Tarn Taran, Naushehra Pannua, 169 m asl, growing in groups on buffalo dung, Amandeep Kaur, 02 August 2010, PUN 4220; Ferozepur, Makhu, $182 \mathrm{~m}$ asl, growing in groups on buffalo dung, Amandeep Kaur, 02 August 2010, PUN 4230; Moga, Chak Kania Wala, $217 \mathrm{~m}$ asl, growing scattered on mixed cattle dung, Amandeep Kaur, 28 June 2011, PUN 4344; Hoshiarpur, Shehbaazpur Tanda, $295 \mathrm{~m}$ asl, growing scattered on mixed buffalo dung and wheat straw, Amandeep Kaur, 03 September 2011, PUN 4343.

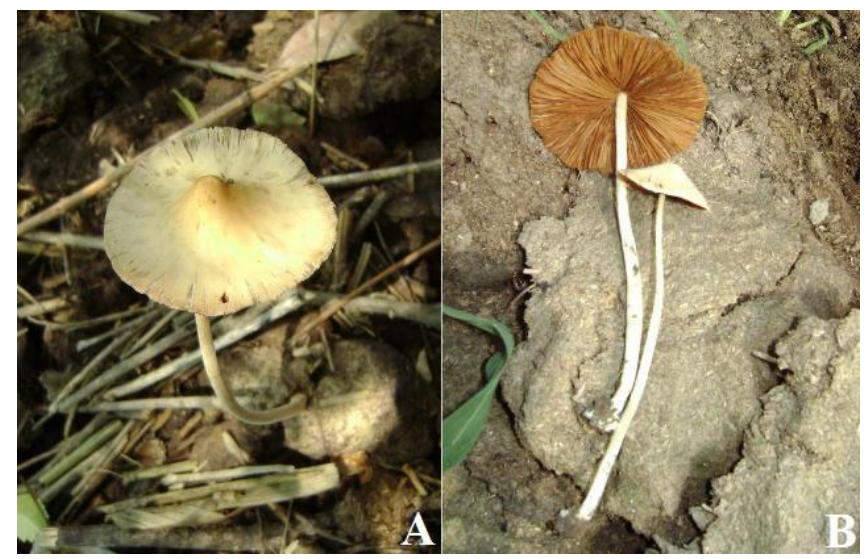

Fig. 8 - Conocybe apala. A. Carpophore growing in natural habitat; B. Pileus undersurface showing yellowish brown lamellae and bulbous stipe base. 
9.2. Discussion - The above examined collections belong to section Pilosellae Singer and series Inocybeoides Hauskn. \& Krisai as they have large carpophores, stipe with bulbous base, large spores, 2- and 4- spored basidia, capilliform pileocystidia, non-lecythiform caulocystidia and absence of pseudoparaphyses (Hausknecht \& Krisai 2006). Conocybe apala can be recognized by large sized carpophores, pale gray hood shaped conical pileus having radially ridged surface and large sized spores (http://en.wikipedia.org/wiki/Conocybe_apala). It is an extremely delicate and ephemeral fungus. Another species belonging to the series Inocybeoides of section Pilosellae is $C$. inocybeoides which is different from the present species in having conical convex to expanded clay buff, milky coffee to mottled sepia pileus, stipe with large emarginate bulb, 2-spored basidia and amygdaliform spores (Watling 1982, Gerault 2005).

Conocybe apala is a saprobic mushroom growing solitary or sometimes in small groups in areas with rich soil and short grass such as pastures, lawns, meadows as well as rotting manured straw. It is a commonly documented fungus in North America and Europe (http://en.wikipedia.org/wiki/Conocybe_apala). During present examination, the species has been observed as widespread in coprophilous habitats of Punjab state in India and recorded frequently from the months of June to September.

10. Conocybe moseri Watling in Notes Roy. Bot. Gard., Edinburgh 38(2): 342, 1980.

Fig. 9

10.1. Synonyms - Conocybe kuehneri Singer in Collect. Bot. 1: 236, 1947.

Conocybe murinacea Watling, 1980.

10.2. Macroscopic Features - Carpophores 4.2-6.2 cm in height, delicate. Pileus $1.2-1.3 \mathrm{~cm}$ broad, 0.6-0.9 $\mathrm{cm}$ high, conical to campanulate; surface dry, grayish white to pale gray when young, grayish brown $\left(6 \mathrm{E}_{3}\right)$ at maturity, smooth; margin regular, not splitting at maturity, striate up to the apex; cuticle not peeling; flesh thin, unchanging; pileal veil absent; taste and odor not distinctive. Lamellae adnate, unequal, 3-sized, subdistant to crowded, narrow, $0.15-0.2 \mathrm{~cm}$ broad, grayish brown $\left(6 \mathrm{E}_{3}\right)$ to yellowish brown $\left(5 \mathrm{E}_{6}\right)$, fragile; gill edges smooth. Spore print yellowish brown (5E 6 ). Stipe central, 4-6 cm long, $0.1-0.15 \mathrm{~cm}$ broad, tubular, equal, thin, twisted, fistulose, solid, surface white $\left(2 \mathrm{~A}_{1}\right)$, bruising yellowish brown, pruinose.

10.3. Microscopic Features - Basidiospores 9.3-13.6 × 6-7.6 (8.5) $\mu \mathrm{m}(\mathrm{Q}=1.6)$, ellipsoidal, with truncate germ pore, thick-walled, smooth, rusty yellow in water, rusty brown in $\mathrm{KOH}$. Basidia 18.7-25.5 × 7.6-10 $\mu \mathrm{m}$, clavate, 4-spored, thin-walled, hyaline, sterigmata 2.5-4.3 $\mu \mathrm{m}$ long. Pseudoparaphyses absent. Gill edges sterile. Cheilocystidia 15.3-23.8 $\times 6-9.3 \mu \mathrm{m}$, lecythiform, thin-walled, hyaline; capitellum 3.4-6 $\mu \mathrm{m}$ broad. Pleurocystidia absent. Pileus cuticle made up of 20.4-34 × 13.6-22 $\mu \mathrm{m}$, polymorphic, subglobose, piriform, clavate or spheropedunculate, thinwalled, hyaline cellular elements; pileocystidia absent; pileus context composed of intermingled, thin walled, hyaline, 8.5-18.7 $\mu \mathrm{m}$ broad hyphae. Hymenophoral trama regular, made up of 3.4-12 $\mu \mathrm{m}$ broad hyphae. Stipe cuticle with non-lecythiform caulocystidia; context hyphae longitudinally parallel, thin-walled, hyaline 3.4-15.3 $\mu \mathrm{m}$ broad; caulocystidia 12-32.3(39) $\times \quad 2.5-6.8 \mu \mathrm{m}$, exclusively non-lecythiform, tubular with loops, cylindrical to hair like filamentous, thin-walled, hyaline. Clamp connections present in stipe context hyphae.

10.4. Chemical Reaction - Ammonia reaction negative.

10.5. Materials Examined - India, Punjab, Moga, Ajitwal, $217 \mathrm{~m}$ asl, growing scattered on mixed cattle dung, Amandeep Kaur, 13 August 2010, PUN 4352; Ludhiana, Lohatbaddi, $254 \mathrm{~m}$ asl, growing in groups on cattle dung, Amandeep Kaur, 14 July 2008, PUN 3898.

10.6. Discussion - The above examined collections fall under series Sienophylla Hauskn. and Krisai of section Pilosellae Singer as they possess small to medium large carpophores and 

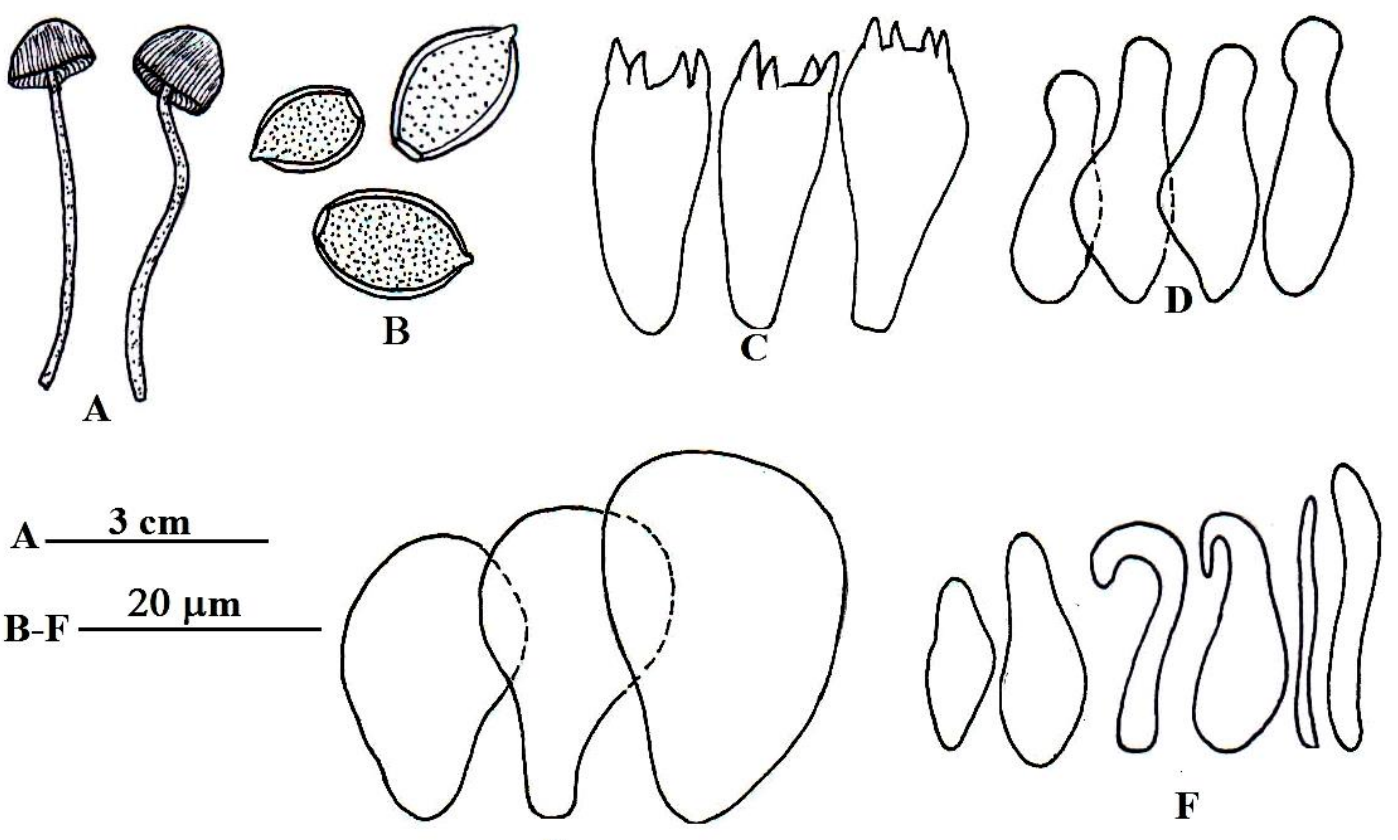

$\mathbf{E}$

Fig. 9 - Conocybe moseri. A. Carpophores; B. Basidiospores; C. Basidia; D. Cheilocystidia; E. Pileal elements; F. Caulocystidia.

distinctly striate pileus (Hausknecht \& Krisai 2006). The macroscopic and microscopic details of the Indian collections fall in the overall taxonomic limits of $C$. moseri as given by Watling (1982) and Prydiuk (2007a) for this species. However, the fresh carpophores of the presently examined collections are neither hazel nor sepia in appearance as described by Watling (1982). But the color tones of both the Indian collections are in conformity with the details given by Prydiuk (2007a) for C. moseri described from Ukraine. The spores are also comparatively larger in the Indian collections $(9.3-13.6 \times 6-7.6(8.5) \mu \mathrm{m})$ in comparison to the spore size $(8.5-11.5(12.5) \times 5-7 \mu \mathrm{m})$ given by Watling (1982). However, in the Ukraine collections the spore size of (8.5)9.5-12 (12.7) $\times$ 5.5-7.5 (8.2) $\mu \mathrm{m}$ (Prydiuk 2007a) is almost comparable to the spore size in the presently examined Indian collections.

Watling (1982) reported this species growing in grassy areas in gardens, fields or at woodland margins from the British Isles. Prydiuk (2007a) reported it growing on soil from Ukraine. Breitenbach \& Kränzlin (1995) documented it from Switzerland, Arnolds (2005) reported it from Europe and Hausknecht et al. (2009) from Russia. Presently it has been found growing in groups on mixed cattle dung for the first time from India.

11. Conocybe velutipes (Velen.) Hauskn. \& Svrček in Czech Mycology 51(1): 68, 1999. Fig. 10

\subsection{Basionym - Galera velutipes Velen. in Novit. Mycol. 128, 1939.}

\subsection{Synonym - Conocybe kuehneriana Singer in Beih. Nova Hedwigia 29: 212, 1969.}

11.3. Macroscopic Features - Carpophores 3.2-5.4 cm in height. Pileus $1.7-2.4 \mathrm{~cm}$ broad, 1.6-2 $\mathrm{cm}$ high, conical; surface moist, brownish orange $\left(6 \mathrm{C}_{7}\right)$ when young, grayish yellow $\left(4 \mathrm{~B}_{5}\right)$ at maturity, smooth; margin irregular, splitting at maturity, striate; cuticle not peeling; flesh thin, unchanging; pileal veil absent; taste and odor not distinctive. Lamellae adnexed, equal, crowded, narrow, up to $0.15 \mathrm{~cm}$ broad, pale yellowish when young, dirty pinkish at maturity, fragile. Stipe central, 3-5.2 cm long, $0.5-0.7 \mathrm{~cm}$ broad, cylindrical, bulbous at the base, solid, surface white $\left(2 \mathrm{~A}_{1}\right)$, bruising brownish, fibrillose. 
11.4. Microscopic Features - Basidiospores 9.3-12.7 × 6.8-7.6(8.5) $\mu \mathrm{m}(\mathrm{Q}=1.52)$, ellipsoidal, with slit-like germ pore, thick-walled, smooth, brownish yellow. Basidia 19.5-30.5 × 10-13.6 $\mu \mathrm{m}$, clavate, 4-spored, thin-walled, hyaline; sterigmata 2.5-3.4 $\mu \mathrm{m}$ long. Pseudoparaphyses absent. Gill edges sterile. Cheilocystidia 17-20.4 (22) $\times$ 5-7.6 $\mu \mathrm{m}$, lecythiform, thin-walled, hyaline; capitellum 2.5-3.4 $\mu \mathrm{m}$ broad. Pleurocystidia absent. Pileus cuticle hymeniform with scattered pileocystidia; cells $15.3-27.3 \times 8.5-13.5 \mu \mathrm{m}$, clavate, thin-walled, hyaline; pileocystidia 20.4-47.6 $\times 1.7-8.5 \mu \mathrm{m}$, polymorphic, elongated filamentous, cylindrical or lecythiform, thin walled, weakly granular; pileus context composed of thin walled, hyaline, 5-13.6 $\mu \mathrm{m}$ broad hyphae. Stipe cuticle having nonlecythiform caulocystidia; stipe context hyphae longitudinally running, thin-walled, hyaline, 3.4$18.7 \mu \mathrm{m}$ broad; caulocystidia $15.3-41 \times 1.7-12 \mu \mathrm{m}$, polymorphic, filamentous, clavate, cylindrical or lageniform, thin-walled, hyaline. Clamp connections present in stipe context hyphae.

\subsection{Chemical Reaction - Ammonia reaction negative.}

11.6. Material Examined - India, Punjab, Moga, Ajitwal, $217 \mathrm{~m}$ asl, growing scattered on cow dung, Amandeep Kaur, 13 August 2010, PUN 4803.

11.7. Discussion - The above examined collection belongs to series Anthracophila Hauskn. \& Krisai of section Pilosellae Singer as it possess strongly colored pileus and large ellipsoidal spores (Hausknecht \& Krisai 2006). It has been identified as C. velutipes. Its macroscopic and microscopic details agree well with those given for this species by Watling (1982), Jordon (1995), Gerault (2005) and Prydiuk (2007a). Conocybe kuehneriana is a synonym of this species as per MycoBank record. Conocybe siennophylla is a similar species but differs from it by relatively smaller basidiospores $(8-11 \times 5-6.5 \mu \mathrm{m})$ and uniformly ochre colored pileus (Watling 1982). Another species which is close to this species is $C$. fuscimarginata but this is different in having clay pink or pinkish cinnamon shades on the pileus and longitudinally striate stipe (Watling 1982).

Conocybe velutipes has been reported growing commonly amongst grasses and mosses from British Isles by Watling (1982). Watling \& Bigelow (1983) reported it growing gregariously in lawn from eastern United States. It is widespread in Europe growing in grasslands from July to September (Watling 1985). Arnolds (2005) reported this species from West and Central Europe. Prydiuk (2007a) recorded it growing on soil from Ukraine. Hausknecht et al. (2009) reported it from Russia and Uzbekistan. The species has already been reported growing scattered on dung manured pots from Malappuram, Kerala (Thomas et al. 2001). It is a new fungus record from North India.

12. Conocybe lenticulospora Watling in Notes Roy. Bot. Gard. Edinburgh 38(2): 351, 1980.

12.1. Synonyms-Mycena brunneidisca Murrill in N. Amer. Flora 10(3): 192, 1917. Bolbitius brunneodiscus (Murrill) Saccardo \& Trotter 1925.

12.2. Macroscopic Features - Carpophores $4.7-5 \mathrm{~cm}$ in height. Pileus $1.7-2 \mathrm{~cm}$ broad, conical to campanulate; umbonate, umbo short, brown; surface dry, yellowish brown $\left(5 \mathrm{E}_{8}\right)$, dark brown $\left(6 \mathrm{~F}_{8}\right)$ towards the margin, hygrophanous, becoming buff in color on drying, smooth; margin regular, reflexed, not splitting at maturity, non-striate; cuticle half peeling; flesh thin, unchanging; pileal veil absent; taste and odor not distinctive. Lamellae adnexed, unequal, 2-sized, subdistant, moderately broad, $0.25-0.3 \mathrm{~cm}$ broad, creamish when young, rusty-brown at maturity, gill edges wavy, fragile. Stipe central, $4.6-4.85 \mathrm{~cm}$ long, $0.2 \mathrm{~cm}$ broad, tubular, with subbulbous base, hollow, surface pale $\left(2 \mathrm{~A}_{2}\right)$, pruinose.

12.3. Microscopic Features - Basidiospores 10-12.8 (13.5) $\times$ 5.7-7 $\mu \mathrm{m}(\mathrm{Q}=1.79)$, lentiform, slightly angular in face view, elongated ellipsoidal in side view, with truncate germ pore, thick- 
walled, smooth, rusty yellow in water, reddish brown in $\mathrm{KOH}$. Basidia 11.4-17 $\times 5.7-8.5 \mu \mathrm{m}$, clavate, 2-, 4-spored, mostly 4-spored, thin-walled, hyaline; sterigmata 2.8-4.3 $\mu \mathrm{m}$ long. Pseudoparaphyses absent. Gill edges sterile. Cheilocystidia 12.8-17 × 3.6-6.4 $\mu \mathrm{m}$, abundant, lecythiform, thin-walled, hyaline; capitellum 2-4.3 $\mu \mathrm{m}$ broad. Pleurocystidia absent. Pileus cuticle hymeniform with scattered pileocystidia; cellular elements 15.6-28.4 × 8.5-15.6 $\mu \mathrm{m}$, clavate or piriform, thin-walled, hyaline; pileocystidia 11.4-42.6 $\times 1.4-2.8 \mu \mathrm{m}$, polymorphic, narrow, thread like, elongated filamentous to capitate, thin walled, hyaline; capitellum 2-2.8 $\mu \mathrm{m}$ broad, with golden contents; pileus context hyphae thin walled, hyaline, 2.8-9.2 $\mu \mathrm{m}$ broad. Hymenophoral trama made up of 4.3-11.4 $\mu \mathrm{m}$ broad hyphae. Subhymenium pseudoparenchymatous. Stipe cuticle with non-lecythiform caulocystidia; stipe context hyphae longitudinally parallel, loosely arranged, thin-walled, hyaline 8.5-28.4 $\mu \mathrm{m}$ broad; caulocystidia 8.5-17 $\times 1.4-5.7 \mu \mathrm{m}$, scattered throughout the context and on the cuticle, polymorphic, clavate, tubular or lageniform, sometimes with swollen base and filamentous loops at the apex, thin-walled, hyaline. Clamp connections present in stipe context hyphae.

\subsection{Chemical Reaction - Ammonia reaction negative.}

12.5. Material Examined - India, Punjab, Lohatbaddi, Ludhiana, $254 \mathrm{~m}$ asl, growing in groups on cattle dung, Amandeep Kaur, 14 July 2008, PUN 4347.

12.6. Discussion - The above examined collection belongs to series Lenticulospora Hauskn. \& Krisai of section Pilosellae Singer as it possesses mycenoid carpophores, slightly bulbous stipe, and lentiform basidiospores (Hausknecht \& Krisai 2006). It has been identified as $C$. lenticulospora. The morphological and anatomical details of this specimen are in conformity with this species as described by Watling (1982). Conocybe hexagonospora closely resembles it but differs in having distinctly hexagonal spores in comparison to slightly angular to broadly ellipsoidal in this species (Watling 1982).

Watling (1982) reported this species growing on horse dung from Scotland. Presently it was found growing on mixed cattle dung for the first time from India.

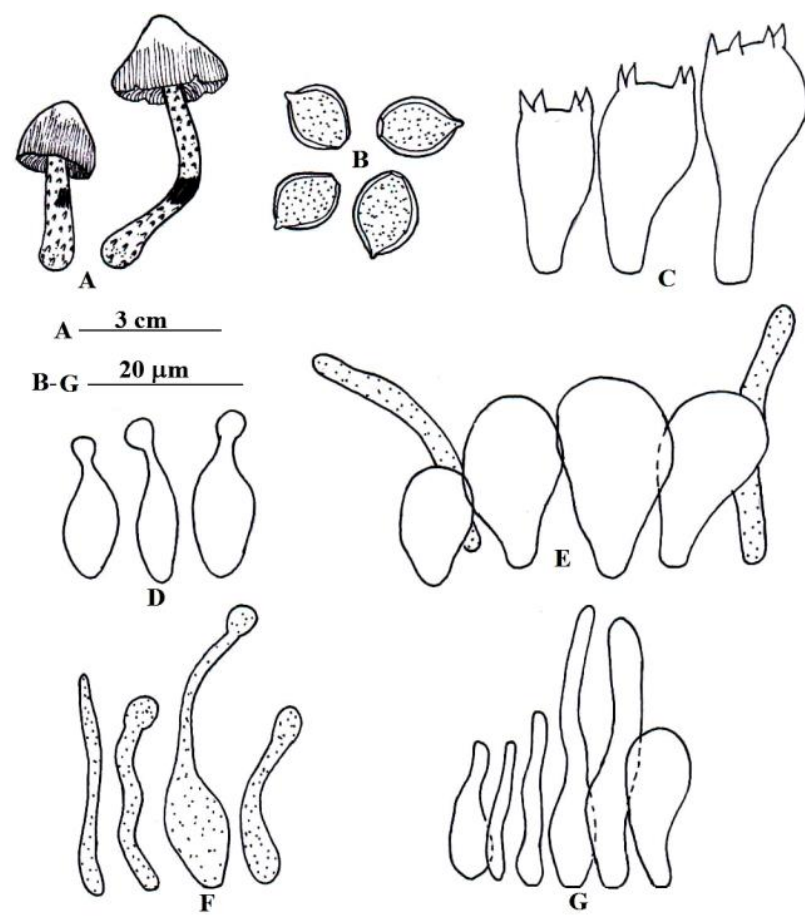

Fig. 10 - Conocybe velutipes. A. Carpophores; B. Basidiospores; C. Basidia; D. Cheilocystidia; E. Pileal elements; F. Pileocystidia; G. Caulocystidia. 


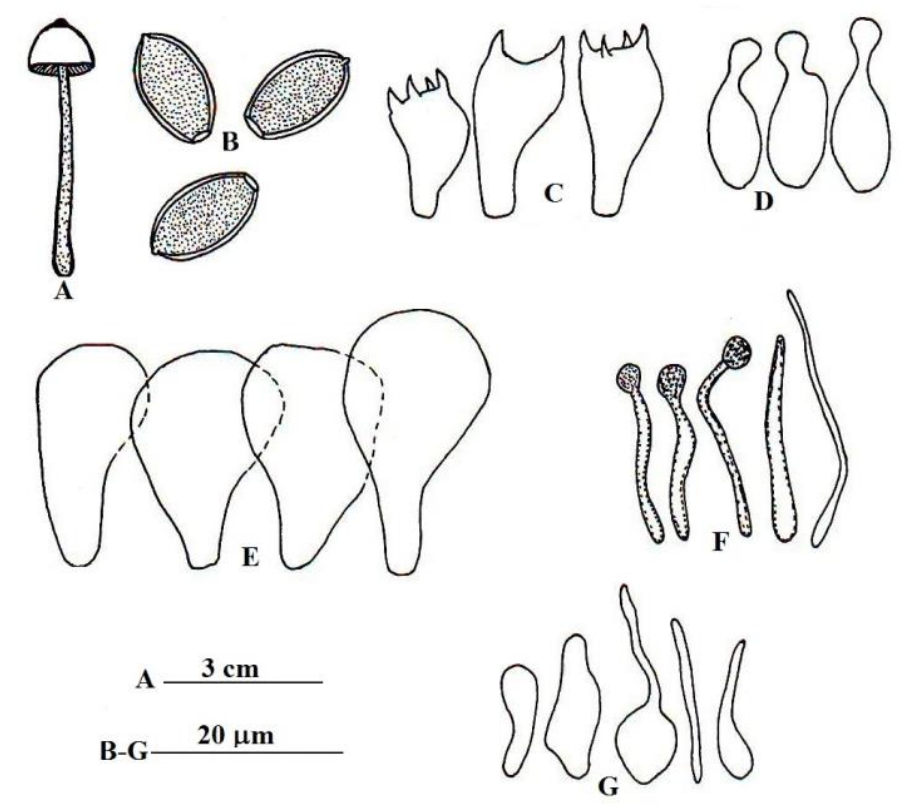

Fig. 11 - Conocybe lenticulospora. A. Carpophore; B. Basidiospores; C. Basidia; D. Cheilocystidia; E. Pileal elements; F. Pileocystidia; G. Caulocystidia.

13. Conocybe fuscimarginata (Murrill) Singer in Beih. Nova Hedwigia 29: 210, 1969. Figs. 12-13

\subsection{Synonym - Galerula fuscimarginata Murrill in Lloydia 5: 148, 1942.}

13.2. Macroscopic Features - Carpophores $4.5-11.5 \mathrm{~cm}$ in height, delicate. Pileus $1.5-1.8 \mathrm{~cm}$ broad, 1-1.5 cm high, conical; surface dry, beige, creamish when young, reddish brown $\left(8 \mathrm{E}_{7}\right)$ at maturity, smooth; margin regular, not splitting at maturity, non-striate; cuticle half peeling; flesh thin, unchanging; pileal veil absent; taste and odor not distinctive. Lamellae adnexed, equal, subdistant, narrow to moderately broad, $0.2-0.3 \mathrm{~cm}$ broad, rusty brown $\left(6 \mathrm{E}_{8}\right)$, fragile; gill edges smooth. Spore print yellowish brown $\left(5 \mathrm{E}_{8}\right)$. Stipe central to slightly eccentric, $4.3-11.4 \mathrm{~cm}$ long, 0.15-0.2 cm broad, cylindrical, with slightly bulbous base, finely striated, twisted, solid, surface white $\left(2 \mathrm{~A}_{1}\right)$ to reddish brown $\left(8 \mathrm{E}_{7}\right)$, pruinose, with cottony mycelium at the base.

13.3. Microscopic Features - Basidiospores 10-12.8(13.5) $\times$ 6-7.8 $\mu \mathrm{m}(\mathrm{Q}=1.65)$, ovoid to ellipsoidal, with truncate germ pore, thick-walled, smooth, rusty golden. Basidia 20.4-27 × 10-13 $\mu \mathrm{m}$, clavate, 2-, 4-spored, mostly 4-spored, thin-walled, hyaline; sterigmata 2.5-4.3 $\mu \mathrm{m}$ long. Pseudoparaphyses absent. Gill edges sterile. Cheilocystidia 17-27 × 3.4-6 $\mu \mathrm{m}$, lecythiform, thinwalled, hyaline; capitellum 3.4-6 $\mu \mathrm{m}$ broad. Pleurocystidia absent. Pileus cuticle hymeniform; composed of 17-27 $\times 13.5-22 \mu \mathrm{m}$, clavate to piriform, thin-walled, hyaline cellular elements; pileocystidia absent; pileus context homoiomerous, made up of intermingled, thin walled, hyaline, 3.5-12 $\mu \mathrm{m}$ broad hyphae. Hymenophoral trama regular, made up of thin walled, 3.5-13.5 $\mu \mathrm{m}$ broad hyphae. Stipe cuticle with non-lecythiform caulocystidia; stipe context hyphae longitudinally running, thin-walled, hyaline 5-27 $\mu \mathrm{m}$ broad; caulocystidia 12-30.6 $\times$ 2.5-4.3 $\mu \mathrm{m}$, non-lecythiform, cylindrical, tubular to elongated filamentous, thin-walled, hyaline. Clamp connections present in stipe context hyphae and basal mycelium.

\subsection{Chemical Reaction - Ammonia reaction negative.}

13.5. Materials Examined - India, Punjab, Patiala, Balbehra, $251 \mathrm{~m}$ asl, growing in groups on cow dung, Amandeep Kaur, 25 June 2008, PUN 4350; Barnala, Farwahi, 228 m asl, growing in groups on mixed cattle dung, Amandeep Kaur, 26 June 2008, PUN 4349. 
13.6. Discussion - The above examined collections belong to section Pilosellae Singer, subsection Siligineae Hauskn. \& Krisai and series Siliginea Watling (Hausknecht \& Krisai 2006). These have been identified as $C$. fuscimarginata. Their taxonomic details are in conformity with those given by Watling (1982) and Gerault (2005) for this species. The species is distinctive by its reddish brown, non-striate pileus, finely striate concolorous stipe, mostly 4-spored basidia and non-lecythiform, cylindrical to elongated filamentous caulocystidia.

Watling (1982) reported the species growing on manured soil and on raw dung from the British Isles. It has also been reported by Watling and Bigelow (1983) growing in manured plant bed from Massachusetts. Kaşik et al. (2004) reported this species growing on goat manure from Turkey. Gerault (2005) recorded it growing on old manure. Hausknecht (2009) found it associated with horse dung from Europe. Hausknecht et al. (2009) reported the species growing in garden and in clayey grassy shore of a stream from Uzbekistan. Doveri (2010) recorded this fimicolous species from cattle dung in Italy. Presently the species has been found growing on cow and mixed cattle dung. It is being reported for the first time from India.

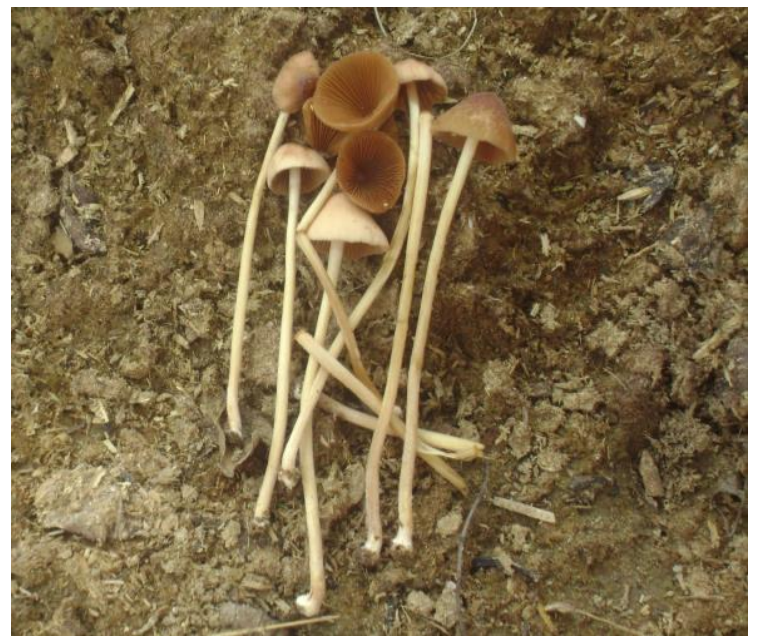

Fig. 12 - Conocybe fuscimarginata. Carpophores in their natural habitat.
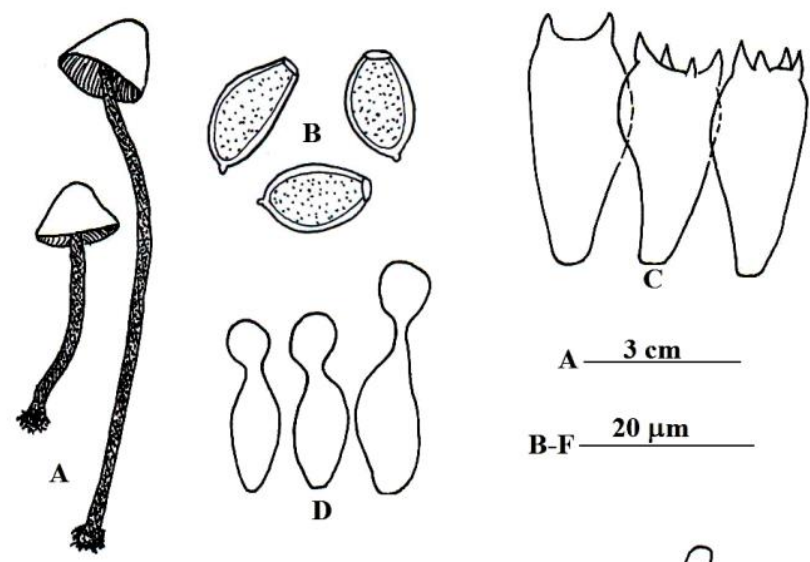

$$
\mathbf{A} \mathbf{c m}
$$

B-F $20 \mu \mathrm{m}$
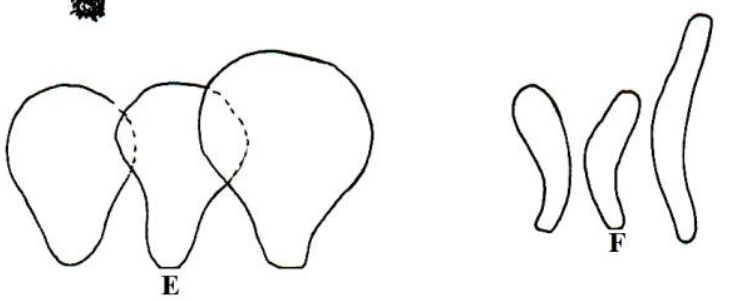

Fig. 13 - Conocybe fuscimarginata. A. Carpophores; B. Basidiospores; C. Basidia; D. Cheilocystidia; E. Pileal elements; F. Caulocystidia. 
14. Conocybe rickenii (Schaef.) Kühner in Encycl. Mycol. 7: 115, 1935.

Figs. 14-15

14.1. Basionym - Galera rickenii Schaef. in Zeits. Pilzk. 9, 1915.

14.2. Synonym - Conocybe siliginea f. rickenii (Schaef.) Arnolds, 2003.

14.3. Macroscopic Features - Carpophore $7.9 \mathrm{~cm}$ in height. Pileus $2 \mathrm{~cm}$ broad, $1.9 \mathrm{~cm}$ high, conical; surface dry, yellowish brown $\left(5 \mathrm{E}_{6}\right)$, smooth; margin regular, not splitting at maturity, nonstriate; cuticle not peeling; flesh thin, unchanging; pileal veil absent; taste and odor not distinctive. Lamellae adnexed, equal, subdistant, narrow, up to $0.25 \mathrm{~cm}$ broad, yellowish white, fragile; gill edges smooth. Stipe central, $8.8 \mathrm{~cm}$ long, $0.3 \mathrm{~cm}$ broad, cylindrical, with bulbous base, hollow, surface white $\left(2 \mathrm{~A}_{1}\right)$, bruising brown, fibrillose.

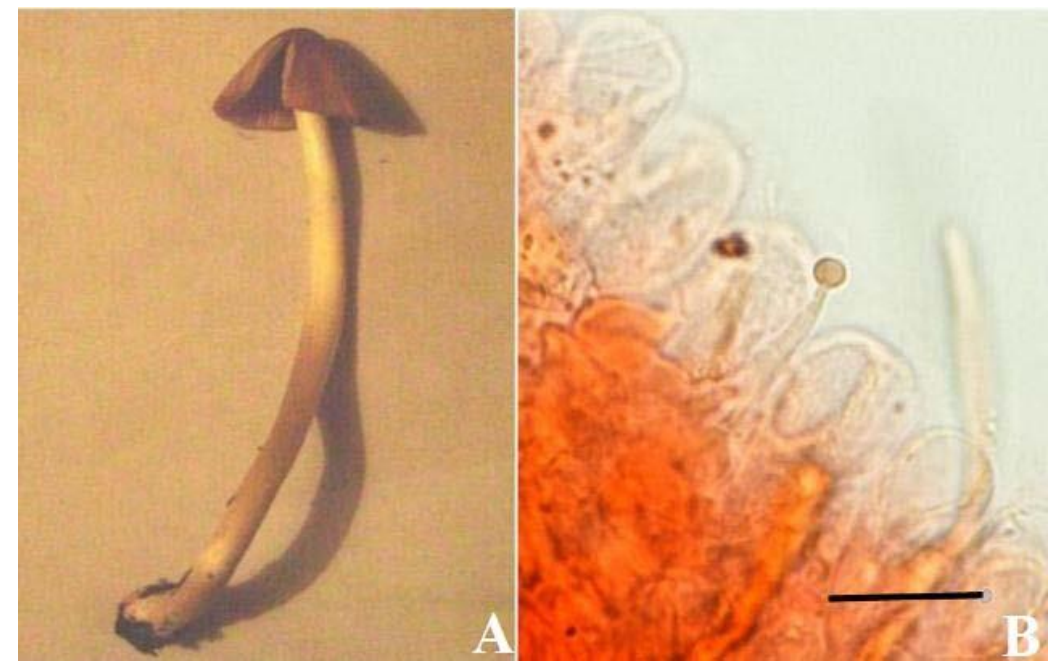

Fig. 14 - Conocybe rickenii. A. Carpophore; B. Pileus cuticle elements. Bar B $10 \mu \mathrm{m}$

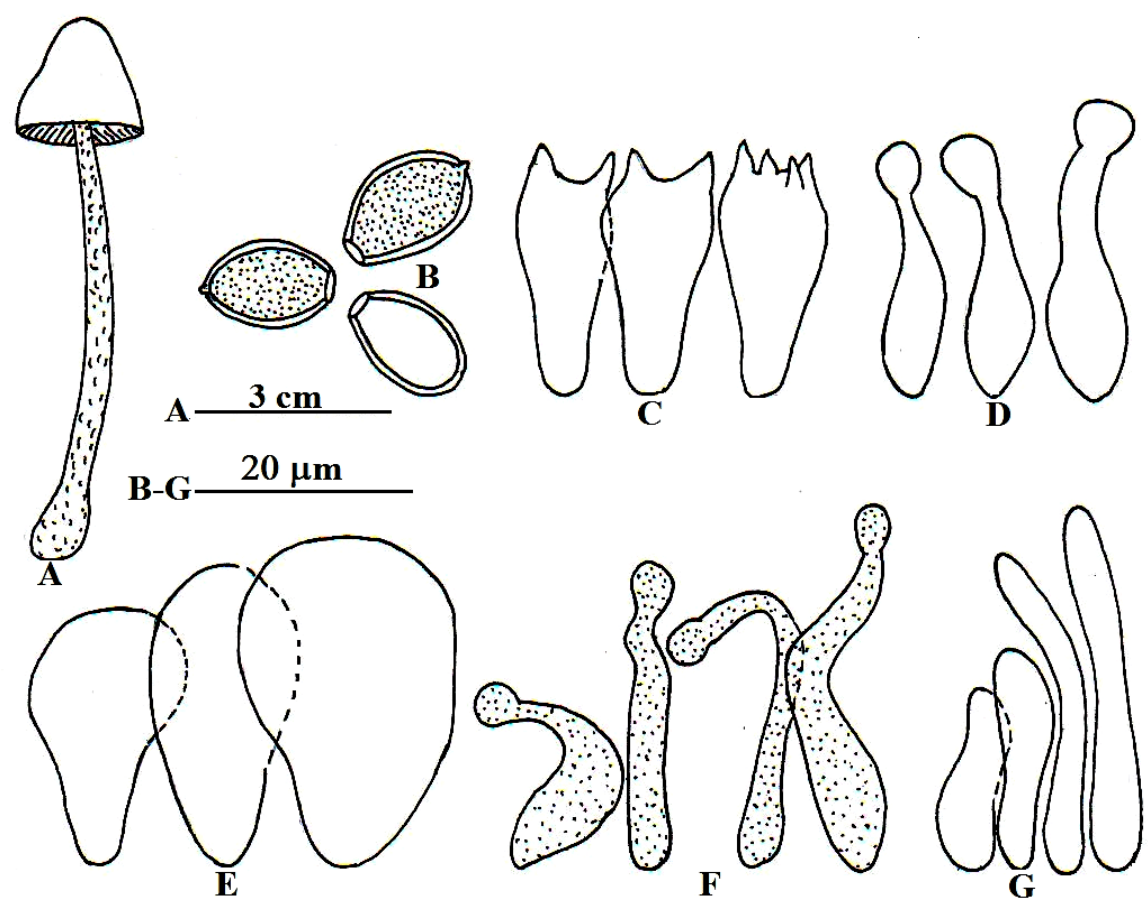

Fig. 15 - Conocybe rickenii. A. Carpophore; B. Basidiospores; C. Basidia; D. Cheilocystidia; E. Pileal elements; F. Pileocystidia; G. Caulocystidia. 
14.4. Microscopic Features - Basidiospores 12-15.3 (16) $\times$ 7.5-9.3 $\mu \mathrm{m}(\mathrm{Q}=1.66)$, ovoid to ellipsoidal, with truncate germ pore, thick-walled, smooth, rusty yellow. Basidia 18.7-22 × 8.5-10 $\mu \mathrm{m}$, clavate, 2- and 4-spored, about $70 \%$ basidia 2-spored, thin-walled, hyaline; sterigmata 2.5 $3.4 \mu \mathrm{m}$ long. Pseudoparaphyses absent. Gill edges sterile. Cheilocystidia 22-27.2 × 5-7.6 $\mu \mathrm{m}$, lecythiform, with long neck, thin-walled, hyaline; capitellum 5-6.8 $\mu \mathrm{m}$ broad. Pleurocystidia absent. Pileus cuticle hymeniform with scattered pileocystidia; cellular elements 20.4-30.4 × 13.5$22 \mu \mathrm{m}$, clavate to piriform, thin-walled, hyaline; pileocystidia 18.7-37.4 × 3.4-7.6 $\mu \mathrm{m}$, lecythiform or elongated filamentous, sometimes forming loops at the apices, thin walled, with golden contents, capitellum 2.5-5 $\mu \mathrm{m}$ broad; pileus context hyphae thin walled, hyaline 3.4-15.3 $\mu \mathrm{m}$ broad. Hymenophoral trama regular, composed of 5-13.6 $\mu \mathrm{m}$ broad hyphae. Stipe cuticle with nonlecythiform caulocystidia; context hyphae longitudinally arranged, thin-walled, hyaline, 5-27 $\mu \mathrm{m}$ broad; caulocystidia 15.3-35.7 × 1.7-5 $\mu \mathrm{m}$, non-lecythiform, clavate, tubular or filamentous, thinwalled, hyaline. Clamp connections present in stipe context hyphae.

\subsection{Chemical Reaction - Ammonia reaction negative.}

14.6. Material Examined - India, Punjab, Sangrur, Jaatimajra, $231 \mathrm{~m}$ asl, growing solitary on buffalo dung, Amandeep Kaur, 13 September 2009, PUN 4351.

14.7. Discussion - The above examined collections belong to section Pilosellae Singer, subsection Siligineae Hauskn. \& Krisai and series Siliginea Watling (Hausknecht \& Krisai 2006). In its gross macroscopic and microscopic details it is quite close to C. rickenii as described by Watling (1982) and Gerault (2005). Watling (1982) reported basidia to be two-spored as compared to Gerault (2005) who has described these to be mostly bisporic. In the presently examined collections majority of the basidia are bisporic.

The species has been documented by Bell (1983) and Watling and Taylor (1987) from New Zealand. Watling (1982) reported it growing on dung in nutrient rich grassland from British Isles. Watling (1985) reported this species growing directly on dung or dung and straw mixtures from Iceland. Gerault (2005) reported it growing on dung, manure or sometimes bare earth pastures. Hausknecht et al. (2009) found it growing on dung from Uzbekistan. Doveri (2010) reported it growing on cattle, donkey and horse dung from Italy. From India, the species was earlier reported growing solitary on the ground from Kodaiknal, Tamil Nadu by Natarajan \& Raaman (1983), growing in caespitose groups or gregariously on horse dung from Chandigarh by Sarwal and Rawla (1983) and growing among grasses along roadside from Sheikhupura, Patiala by Atri et al. (1992).

15. Conocybe crispa (Longyear) Singer in Lilloa 22: 485, 1951.

\subsection{Basionym - Galera crispa Longyear in Bot. Gaz. 28: 272, 1899.}

\subsection{Synoonyms - Galerula crispa (Longyear) Murrill 1917.}

Bolbitius crispus (Longyear) Bon 1990.

Conocybe albipes var. crispa (Longyear) Hauskn. 1998.

15.3. Material Examined - India, Punjab, Sangrur, Upoki, 231m asl, growing in caespitose cluster on partially decomposed buffalo dung flake, Amandeep Kaur, 20 August 2008, PUN 3897.

15.4. Discussion - This species belongs to series Albipes Hauskn. \& Krisai of section Candidae Singer as it possesses pale colored pileus, slightly deliquescent gills and prominent pseudoparaphyses in the hymenium (Watling 1982, Hausknecht \& Krisai 2006). Watling (1982) described the basidia as only 2-spored in C. crispa as compared to basidia described as bearing four short sterigmata in this species by Pegler (1977). In the presently examined collection both 2- and 4-spored basidia has been documented. 
Longyear (1899) originally described the species growing amongst grasses as Galera crispa. Pegler (1977) reported it growing solitary on fallen leaves of bamboo from Kenya. Watling (1982) recorded it growing in river valley meadow from Yorkshire. Atri et al. (2009) reported it as a new record from India.

16. Conocybe albipes (G.H. Otth) Hauskn. in Österreichische Zeitschrift für Pilzkunde 7: 102, 1998.

\subsection{Basionym - Bolbitius albipes G.H. Otth in Mitt. Naturf. Ges. Bern 92, 1871.}

16.2. Synonyms - Bolbitius lacteus J.E. Lange in Flora Agaricina Danica 5:2, 1940.

Conocybe lactea (J.E. Lange) Métrod in Bulletin de la Société Mycologique de France 56:46, 1940. Conocybe apala var. albipes (G.H. Otth) Arnolds in Persoonia 18(2): 227, 2003.

16.3. Macroscopic Features - Carpophores 9.5-12.2 cm in height. Pileus 1.5-2.2 cm broad, 1.3-1.7 $\mathrm{cm}$ high, conical to convex; umbonate, umbo broad, white; surface white, dry, smooth; margin irregular, not splitting at maturity, striated, sometimes reflexed; cuticle not peeling; flesh very thin, white, unchanging; pileal veil absent; taste and odor not distinctive. Lamellae adnexed to free, equal, subdistant, narrow, up to $0.2 \mathrm{~cm}$ broad, golden brown; gill edges smooth, white. Stipe central, $9.4-12 \mathrm{~cm}$ long, $0.3-0.5 \mathrm{~cm}$ broad, cylindrical, with distinctly bulbous base, first solid then hollow, surface white, unchanging, pruinose.

16.4. Microscopic Features - Basidiospores 12-13.6 (14.4) × 7.6-9.3 $\mu \mathrm{m}(\mathrm{Q}=1.5)$, lentiform, ellipsoidal, with a truncate germ pore, thick-walled, smooth, rusty yellow. Basidia 18.7-25.5 × 1013.6 $\mu \mathrm{m}$, clavate, 4- spored, thin walled, hyaline; sterigmata 2.5-4.3 $\mu \mathrm{m}$ long; pseudoparaphyses present between the basidia. Gill edges sterile. Cheilocystidia 17-23 $\times$ 5-6.8 $\mu \mathrm{m}$, lecythiform, thinwalled, hyaline; capitellum 3.4-4.3 $\mu \mathrm{m}$ broad. Pleurocystidia absent. Pileus cuticle hymeniform with scattered hairs; cellular elements 18.7-42.5 × 12-17 $\mu \mathrm{m}$, clavate to sphaeropedunculate, thin walled, hyaline; pileocystidia absent; pileus context homoiomerous, composed of 5-12 $\mu \mathrm{m}$ broad hyphae. Subhymenium pseudoparenchymatous. Stipe cuticle hyphal having non-lecythiform caulocystidia; caulocystidia 18.7-25.5 $\times$ 5-8.5 $\mu \mathrm{m}$, polymorphic, cylindrical, clavate to sublageniform, thin-walled, hyaline; stipe context made up of longitudinally running, thin-walled, hyaline 6.8-25.5 $\mu \mathrm{m}$ broad hyphae. Clamp connections absent.

\subsection{Chemical Reaction - Ammonia reaction negative.}

16.6. Material Examined - India, Punjab, Chhat Bir, $251 \mathrm{~m}$ asl, growing scattered in a group on elephant dung mixed with rotten wheat straw and leaf litter, Amandeep Kaur, 19 September 2011, PUN 4799.

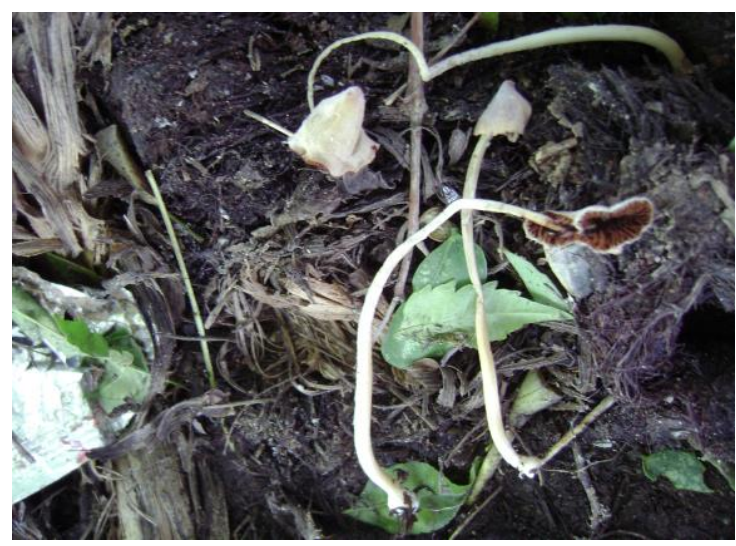

Fig. 16 - Conocybe albipes. Carpophores growing in natural habitat. 


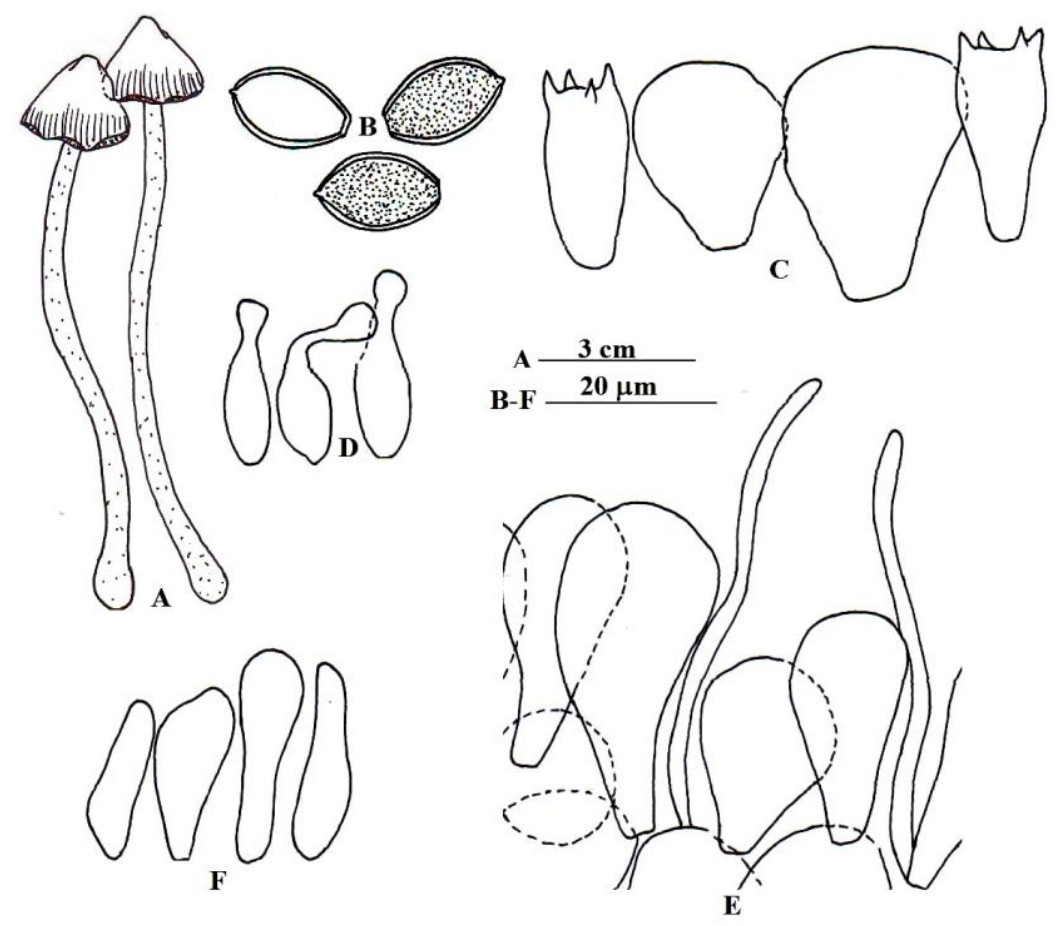

Fig. 17 - Conocybe albipes. A. Carpophores; B. Basidiospores; C. Basidia and Pseudoparaphyses; D. Cheilocystidia; E. Pileal elements; F. Caulocystidia.

16.7. Discussion - The presently examined collection fall under series Albipes Hauskn. \& Krisai in section Candidae Singer. It resembles the description of Conocybe lactea as given by Watling (1982). According to MycoBank, C. lactea is a synonym of C. albipes. The species is a small, very fragile, white mushroom having obtusely conical, umbonate pileus, striate margin which sometimes become reflexed in age, 4- spored basidia and golden-brown gills with white edges (Arnolds 2005). It can be differentiated from $C$. apala in being much smaller, more delicate in stature and by the presence of pseudoparaphyses in the hymenium. Conocybe crispa differs by crisped gills and mostly 2-spored basidia.

This species was reported growing in grassy areas, parkland, gardens and meadows from all major areas of the British Isles as C. lactea (Watling 1982). It has also been reported from Netherlands (Arnolds 2005). Presently it has been recorded from the coprophilous habitat for the first time from India.

\section{Conclusion}

In the present study, it is concluded that Conocybe mushrooms show wide distribution and diversity amongst different regions, dung types, seasons, and growing habits of Punjab in India. The identified species of Conocybe, namely C. albipes, C. apala, C. brachypodii, C. crispa, C. fuscimarginata, C. lenticulospora, C. leucopus, C. magnicapitata, C. microrrhiza var. coprophila, C. moseri, C. rickenii, C. subpubescens, $C$. subxerophytica var. subxerophytica, C. subxerophytica var. brunnea, C. uralensis and C. velutipes, were quite frequent in Punjab state in India. They were collected growing on five diverse dung types including mixed, buffalo, cow, horse, and elephant dung. As many as 12 species, namely Conocybe subxerophytica var. brunnea, C. leucopus, C. magnicapitata, C. subpubescens, C. uralensis, C. microrrhiza var. coprophila, C. moseri, C. velutipes, C. lenticulospora, C. rickenii, C. crispa and C. albipes, were available exclusively in monsoon season while three species, namely Conocybe brachypodii, C. subxerophytica var. subxerophytica and $C$. fuscimarginata were collected during summer season. Conocybe apala was encountered in both monsoon and summer seasons. They were found growing solitary, scattered, and also in caespitose clusters. Conocybe brachypodii, $C$. subxerophytica var. subxerophytica, $C$. subxerophytica var. brunnea, C. leucopus, C. subpubescens, C. uralensis, C. moseri, C. velutipes, 
C. lenticulospora, $C$. fuscimarginata and C. albipes were noted growing either scattered or in small groups. Conocybe magnicapitata, C. microrrhiza var. coprophila and $C$. rickenii were observed solitary in growing habit. Conocybe crispa was found growing in caespitose clusters. Conocybe apala was observed frequently, growing solitary to scattered.

Dung is an important substrate which serves as a favorable niche for the growth of a variety of fungi including mushrooms. But the natural habitats with dung deposits such as pastures, grasslands, etc. are getting destroyed because of the various developmental activities. Pasture management is an important area which needs to be looked into for the favorable habitats of coprophilous mushrooms. Livestock, in agriculture based societies like Punjab state in India, should be managed in a manner which favors their grazing in the wild places. Coprophilous mushrooms are often delicate and short-lived. Any loss to their habitats will directly impact their diversity. These fungi must be conserved as they play a significant role in the decomposition of organic matter and maintenance of ecological balance on the earth.

\section{Acknowledgements}

The authors wish to thank Punjabi University, Patiala, Punjab for providing laboratory facilities and University Grants Commission, New Delhi for financial assistance under SAP-III programme of D.R.S.

\section{References}

Arnolds E 2005 - Bolbitiaceae. In: Flora Agaricina Neerlandica 6, Coprinaceae and Bolbitiaceae (eds ME Noordeloos, TW Kuyper, EC Vellinga). Boca Raton, London, New York, Singapore, Taylor \& Francis.

Atri NS, Kaur A, Kour H. 2005 - Wild mushrooms- collection and identification. In: Frontiers in Mushroom Biotechnology (eds RD Rai, RC Upadhyay, SR Sharma), National Research Center for Mushroom, Chambaghat, Solan, India, pp 9-26.

Atri NS, Kaur A, Kaur M. 2009 - Three new records of coprophilous mushrooms of family Bolbitiaceae from India. Mushroom Research 18 (2), 51-56.

Atri NS, Kaur M, Kaur A. 2012 - Taxonomic studies on some coprophilous species of Conocybe from India. Mushroom Research 21 (2), 103-109.

Atri NS, Saini SS. 2000 - Collection and study of Agarics- An introduction. Indian Journal of Mushrooms 18(1\&2), 1-5.

Atri NS, Saini SS, Kaur G. 1992 - Taxonomic studies on some members of family Bolbitiaceae Sing. from Punjab. Journal of the Indian Botanical Society 71(1-2), 87-89.

Bell A 1983 - Dung Fungi. An Illustrated Guide to Coprophilous Fungi in New Zealand. Victoria University Press, Private Bag Wellington, pp 88.

Bilgrami KS, Jamalludin S, Rizwi AM. 1991 - Fungi of India. List and References. Today and Tomorrow's Printers and Publishers, New Delhi, India, pp 798.

Breitenbach J, Kränzlin F. 1995 - Fungi of Switzerland. Vol 4. Verlag Mykologia, pp 368.

Doveri F 2010 - Occurrence of coprophilous Agaricales in Italy, new records, and comparisons with their European and extraeuropean distribution. Mycosphere 1(2), 103-140.

Gérault A 2005 - Florule Evolutive des Basidiomycotina du Finistère. Homobasidiomycetes, pp 183.

Hausknecht A, Kalamees K, Knudsen H, Mukhin V. 2009 - The genera Conocybe and Pholiotina (Agaricomycotina, Bolbitiaceae) in temperate Asia. Folia Cryptogamica Estonica, Fasc 45, $23-47$.

Hausknecht A 2002 - Beitrage zur Kenntnis der Bolbitiaceae 7. Die Conocybe tenera-Gruppe, Teil 2, und eine Revision der Arten um Conocybe mesospora in Europa. Österreichische Zeitschrift für Pilzkunde 11, 35-77.

Hausknecht A 2009 - A monograph of the genera Conocybe Fayod and Pholiotina Fayod in Europe. Fungi Europaei (Ed. Candusso), Alassio. 
Hausknecht A, Krisai-Greilhuber I. 2006 - Infrageneric division of the genus Conocybe- a classical approach. Österreichische Zeitschrift für Pilzkunde 15, 187-212.

Jordon M 1995 - The Encyclopedia of Fungi of Britain and Europe. David and Charles Book Company Devon, pp 249. ISBN 0715301292

Kaşik G, Doğan H, Öztürk C, Aktaş S. 2004 - New records in Coprinaceae and Bolbitiaceae from Mut (Mersin) District. Turkish Journal of Botany 28, 449-455.

Kirk PF, Cannon PF, Minter DW, Stalpers JA. 2008 - Ainsworth and Bisby's Dictionary of Fungi, 10th ed, CABI Bioscience, CAB International, UK.

Kornerup A, Wanscher JH. 1978 - Methuen Handbook of Colour, 3rd ed, Eyre Methuen, London.

Kumar M, Harsh NSK, Prasad R. 2014 - Conocybe apala (Fr.: Fr.) Arnolds, Helvella solitaria P. Karst. and Hygrocybe miniata (Fr.) P. Kumm.; three new mushrooms from India. Current Research in Environmental \& Applied Mycology 4(1), 100-105, Doi 10.5943/ream/4/1/

Longyear BO 1899 - Two new Michigan fungi. Botanical Gazette 28, 272-273.

Manimohan P, Thomas KA, Nisha VS. 2007 - Agarics on elephant dung in Kerala State, India. Mycotaxon 99, 147-157.

Natarajan K, Raaman N. 1983 - South Indian Agaricales. Bibliotheca Mycologica 89, 1-203.

Natarajan K, Kumaresan V, Narayanan K. 2005 - A checklist of Indian Agarics and Boletes (19842002). Kavaka 33, 61-128.

Pegler DN 1977 - A Preliminary Agaric flora of East Africa. Kew Bulletin Additional Series 6, London. pp 615.

Pegler DN 1983 - Agaric flora of the lesser Antitles. Kew Bulletin Additional Series 9, London. pp 668.

Pegler DN 1986 - Agaric flora of Sri Lanka. Kew Bulletin Additional Series 12, London. pp 514.

Prydiuk MP 2007a - New records of Conocybe species from Ukraine. I. The sections Mixtae and Pilosellae. Česká Mykologie 59 (1), 25-38.

Prydiuk MP 2007b - New records of Conocybe species from Ukraine. II. The section Conocybe. Česká Mykologie 59(1), 39-50.

Saini SS, Atri NS. 1995 - Mushroom flora of Punjab. In: Advances in Horticulture Vol 13Mushrooms (eds KL Chadha, SR Sharma). Malhotra Publishing House, New Delhi, India, pp 375-386.

Sarwal BM, Rawla GS. 1983 - Taxonomic studies on Indian Agarics-III. Bibliotheca Mycologica 91, 541-548.

Singer R 1986 - The Agaricales in Modern Taxonomy, 4th ed, Sven Koeiltz Scientific Books, Germany. pp 981.

Smith AH 1949 - Mushrooms in their Natural Habitats. Hafner Press, New York, pp 626.

Thomas KA, Hausknecht A, Manimohan P. 2001 - Bolbitiaceae of Kerala State, India, new species and new and noteworthy records. Österreichische Zeitschrift für Pilzkunde 10, 87-114.

Watling R 1982 - British Fungus Flora- Agaric and Boleti 3. Bolbitiaceae: Agrocybe, Bolbitius, Conocybe, Edinburgh, HMSO, UK.

Watling R 1985 - The Agaricales of Iceland- VI. Icelandic species of Bolbitiaceae. Observations on the Bolbitiaceae: 25. Acta Botanica Islandica 8, 3-19.

Watling R, Bigelow HE. 1983 - Observations on the Bolbitiaceae-22. Mycotaxon 17, 377-397.

Watling R, Gregory NM. 1980 - Larger fungi from Kashmir. Nova Hedwigia 32, 493-564.

Watling R, Taylor GM. 1987 - Observations on the Bolbitiaceae. Bibliotheca Mycologia, $27 \mathrm{~J}$ Cramer, Berlin, Stuttgart. 